\title{
Double moral hazard in a supply chain with consumer learning
}

By: Jianheng Zhou, Xia Zhao, Ling Xue, and Vidyaranya Gargeya.

Zhou, J., Zhao, X., Xue, L., Gargeya, V. B. (2012). Double moral hazard in a supply chain with consumer learning. Decision Support Systems, 54: 482-495.

Made available courtesy of Elsevier: http://dx.doi.org/10.1016/j.dss.2012.06.011

***@@ Elsevier. Reprinted with permission. No further reproduction is authorized without written permission from Elsevier. This version of the document is not the version of record. Figures and/or pictures may be missing from this format of the document. ***

\section{cc) (i) $\ominus$}

EY No NO This work is licensed under a Creative Commons AttributionNonCommercial-NoDerivatives 4.0 International License.

\begin{abstract}
:
When an innovative product is introduced into the market, consumers are often uncertain about the product value. Over time they may learn the value of product. This paper studies the impact of consumer learning on the firms' marketing efforts and revenue sharing strategies in a supply chain that sells an innovative product to consumers over multiple periods. Both the supplier and the retailer can exert marketing efforts to influence consumers' beliefs about the product and improve the product demand. Because the supplier and the retailer are independent entities with self-interested objectives, double moral hazard exists in the supply chain. We find that the supplier and retailer exert more marketing efforts in the presence of consumer learning but the marketing efforts decrease as consumers learn more about the product. We also examine the revenue-sharing strategies and find that supplier shares more revenue to the retailer when they cooperate for a longer time horizon. The total profit of the supply chain may be higher when there is information asymmetry between the supplier and retailer. This finding suggests that information sharing is not always beneficial to improve supply chain coordination.
\end{abstract}

Keywords: Supply chain | Moral hazard | Consumer learning | Information sharing

Article:

\section{Introduction}

Valuation uncertainty often arises when innovative products are introduced into the consumer market. The consumers, without experiencing the innovative products, can rarely predict with certain- ty the values of the products [19]. For example, when a new hybrid car is launched, a consumer might not be able to predict its fuel efficiency and battery life. When a new game console is released, a consumer might not be able to anticipate precisely the diversity and amusement of the games compatible with the console. Other newly innovated electronic products, such as smart phones and tablet computers, have similar issues. This scenario is also prevalent in agribusiness, software, and apparel industries. 
Over time consumers may obtain more information about a product from multiple sources and evaluate the product better [23]. For example, the consumers can view professional product reviews from magazines or peer consumer reviews published online $[8,12]$. They can also learn the historical sales prices and sales numbers of products via e-commerce websites or through companies' earnings releases. For example, eBay posts the past transaction records of listing items on its listing page; Apple's earnings report disclosed the sales numbers of its flagship products-17.07 million iPhones and 11.12 million iPads during the last quarter of 2011 [1]. Compared with professional and consumer product reviews, product sales numbers are more difficult to be manipulated and hence convey more reliable information about the product. In this paper, we focus on consumer learning through product sales.

Firms in a supply chain often exert marketing efforts to change their consumers' perceptions of the product values. Purchasing television or online advertisements, hiring public relationship companies to publish positive product articles in magazines, and/or offering various promotional incentives such as gift with purchase and next purchase discount are some of the mechanisms by which firms attempt to influence consumer perceptions. It has been recognized that marketing activities in the supply chain often generate positive externalities [14]. As one firm's marketing effort improves the brand image and boosts the product demand, all firms participating in the supply chain may benefit. However, in most practical situations, the full scope of the firm's actions (including marketing efforts) is not observable by other firms in the supply chain. The firm may avoid spending on the costly (and sometimes unobservable) marketing effort be- cause it would not like to share the resultant benefit with its supply chain partners. This is how double moral hazard arises $[2,15]$.

In this paper, we consider a supply chain with consumer learning and double moral hazard. The supply chain consists of supplier, retailer, consumer and has the following features. First, the consumers are uncertain about the true value of the innovative product. Over time, the consumers may learn more about the product value from prior sales of the product. In particular, higher product sales signal a higher product value to the consumers, which yields a higher product demand. Second, the firms (both the supplier and retailer) in the supply chain can exert marketing efforts to change the product sales. Finally, a firm's marketing effort is unobservable by any other firm or consumers in the supply chain. This leads to the issue of double moral hazard.

This paper aims to explore the impact of consumer learning on the firms' marketing strategies and supply chain coordination in the presence of double moral hazard. In particular, this paper answers the following questions. First, when the consumers are uncertain about the true value of a new product and learn the product value from prior sales, how do the supplier and retailer exert marketing efforts to improve the product demand? Do the marketing efforts increase or decrease over a period of time? Compared with the case without consumer learning, do the firms exert more or less marketing efforts? The answers to these questions provide important implications on understanding the firms' marketing strategies.

The second issue concerns the impact of consumer learning on sup- ply chain coordination. We consider a linear revenue-sharing scheme in which the supplier decides the revenue sharing ratio. 
There are several questions that need to be addressed. How do the firms share the revenue in the supply chain in the presence of consumer learning? Is the supplier willing to share more or less revenue with the retailer when the two entities cooperate over a longer time horizon? Compared with the case without consumer learning, does the supplier share more or less revenue with the retailer? The answers to these questions help us gain greater insight on supply chain coordination for innovative products.

The third and last issue relates to the role of information in the supply chain with consumer learning and double moral hazard. Conventional wisdom suggests that information asymmetry undermines supply chain coordination and firms therefore strive to eliminate in- formation asymmetry. With consumer learning, does double moral hazard still undermine the profit of the supply chain? Should the sup- ply chain always eliminate information asymmetry between the trade partners? A better understanding of the role of information enables the entities in the supply chain to improve the management of information in the supply chain.

Our research results depict several interesting findings. We find that the supplier and retailer exert more marketing efforts to increase the product demand in the case with consumer learning compared with that without consumer learning. This result holds even though the consumers always correctly predict the firms' demand-boosting strategies and adjust their beliefs. Over time, consumers learn more and predict the product value more accurately. As a result, firms exert less marketing efforts because the efforts have less impact on the consumers' perception.

The revenue sharing ratio is higher when the entities in the supply chain cooperate over a longer time horizon. A higher revenue sharing ratio decreases the supplier's incentive to exert effort whereas consumer learning negates this effect. Compared with the case without consumer learning, the supplier shares more revenue to motivate the retailer to increase the latter's effort. With a longer time horizon, the impact of consumer learning on the supplier's marketing effort is stronger, leading to a higher revenue sharing ratio.

This paper also has a counterintuitive finding about the role of in- formation. The results show that the total profit of the entities in the supply chain may be higher when there is asymmetric information between the supplier and the retailer. This stands in contrast to the findings in the existing literature that double moral hazard under- mines the total profit of firms. With double moral hazard, the firms in the supply chain tend to exert less effort because the benefit will be split amongst the partners. In this paper, we find that consumer learning motivates firms to exert higher marketing efforts. This positive effect of consumer learning mitigates the adverse consequences of double moral hazard. When the supplier has complete information and thereby decides the marketing efforts for all the entities in the supply chain, the supplier demands too much marketing efforts for the purpose of misleading consumers. Therefore, better information in the supply chain does not always improve the profit of the supply chain. Double moral hazard may be beneficial in presence of consumer learning. This is one of the major findings of this research.

The paper is organized as follows. Section 2 reviews the related literature. Section 3 outlines the model. Sections 4 and 5 analyze the cases without consumer learning and with consumer 
learning respectively. Section 6 compares the results in different cases and conclusions are presented in the last section of the paper.

\section{Literature Review}

This paper draws upon and contributes to several streams of literature as reviewed in this section. First, this paper relates to the literature on moral hazard. There is a large body of literature examining the issue of moral hazard in supply chains $[4,6,7]$. These studies only consider the agency issues on the retailer side. In many practical situations, both the suppliers and retailers can invest in costly efforts to improve the performance of the supply chains. In this paper, we consider both parties' efforts which comes down to a double moral hazard problem.

Double moral hazard has also been examined in the literature. Holmstrom examines moral hazard in team (partnership) and shows that any sharing rule subject to the budget balancing constraint cannot achieve the first-best outcome in team production [13]. Corbett and Decroix consider a supply chain where the consumption of indirect materials is endogenously determined by both the supplier's and the retailer's efforts [5]. The supplier and retailer have countervailing incentives to exert consumption-reduction efforts as the retailer saves but the supplier loses from a reduced consumption. They find that a simple shared- savings contract is possible to increase channel profits. Lal studies the royalty structure and the monitoring technology of revenue sharing con- tracts in a franchising setting [16]. He finds that a contract with royalty fee can provide appropriate incentives to both the franchisor and the franchisee. Bhattacharyya and Lafontaine model a principal and agent problem with double moral hazard [2]. They show that a simple linear contract in which the principal and the agent share the output in addition to a fixed monetary transfer yields the second-best outcome (complete information results in the first-best outcome). Eswaran and Kotwal investigate the use of revenue-sharing contract in the presence of double moral hazard [9]. They find that a revenue sharing contract is advantageous when the class structure is polarized - the landlord lacks production capability and the tenants have little management capability. The current paper contributes to this stream of literature by investigating double moral hazard in the presence of consumer learning.

This paper also relates to the literature on supply chain coordination with strategic consumers, who decide on the timing of purchase. Su and Zhang study a newsvendor problem with forwardlooking consumers who can rationally anticipate future product sales and availability [22]. They find that the seller's stocking level is lower in the case with strategic consumers as opposed to the case with nonstrategic consumers and a decentralized supply chain yields a higher profit. Swinney investigates the value of quick response production for a firm selling to a forwardlooking consumer population [23]. The consumers are uncertain about their valuations for the product at the start of the selling sea- son but learn their valuations upon receiving private signals later. Swinney finds that the quick response strategy does not always improve the firm's profit with strategic consumers [23].

Recently a number of papers consider consumer learning using multi-period models. Gallego, et al. investigate a firm's optimal pricing policy when the firm's markup policy in the current season changes the consumers' expectation and purchasing behaviors in future seasons [10]. Gallego et al. find that a single-price policy is optimal if all consumers are strategic and demand is known to 
the seller [10]. Ovchinnikov and Milner numerically illustrate the value of offering end-of-period deals when consumers learn to expect the firm's discount policy and wait to buy [21]. They consider consumers with heterogeneous valuation on the product and different types of learning dynamics (self-regulating and smoothing function). Liu and van Ryzin study a capacity rationing problem with a supplier selling to consumers over repeated seasons [18]. Even though the consumers can observe the supplier's past capacity, they cannot anticipate product availability perfectly. The consumers form their expectations about product availability through a smoothing rule with an exogenous specified constant learning factor. Gaur and Park model the retailers' inventory decisions and analyze the competition taking account of asymmetric consumer learning [11]. The consumers up- date their beliefs on the service level by associating different weights with the positive and negative experiences. The previous papers explore the firms' (suppliers' and retailers') pricing, rationing and inventory decisions with consumer learning. Our paper focuses on the firms' marketing decisions in a supply chain with consumer learning.

\section{Model}

We model a supply chain with a supplier and a retailer marketing and selling an innovative product over multiple periods. We assume that both the supplier and the retailer are monopolists in the whole- sale and consumer markets respectively, as done by $\mathrm{Su}$ [22] and Swinney [23]. In each period, there is a constant flow of new consumers entering the consumer market. In many practical situations, potential consumers are uncertain about the true value of innovative product but they can learn the product value. A consumer's belief of product value is often affected by the behavior of the prior consumers. For example, the consumers can acquire more information from online professional or customer review $[8,12]$. In addition to product reviews, an important source for consumers to learn product values is product sales. Product sales reflect the collective behavior of past consumers. Compared to online reviews, the product sales is more difficult to be manipulated, and hence is more likely to carry trustworthy information about the true value of the product. In this paper, we focus on consumer learning through product sales.

We assume that the price of the innovative product is fixed. Let it be $p$. Fixed prices for new products are often seen in the retailing sectors such as mobile phones (e.g., iPhones and HTC phones), computing devices (e.g., iPads and Motorola Xoom) and software applications (e.g., Auto CAD and Div X). The assumption of fixed price has been widely used in the literature on supply chain management $[3,4,22]$. We use $\theta$ to denote the consumer demand. In most practical situations, the higher the product value is, the more consumers are willing to buy the product. Therefore, $\theta$ can be considered as a proxy of the product value. For example, suppose that the utility of a consumer from purchasing and using the product is $\alpha \mathrm{V}-\mathrm{p}$ where $\mathrm{V}$ represents the value of the product and $\alpha$ characterizes a consumer's preference. The consume whose preference parameter is higher than $\mathrm{p} \mathrm{V}$ will purchase this product. If $\alpha$ is uniformly distributed between 0 and 1, we have $\theta 1 / 41-\mathrm{p} \mathrm{V}$. The consumer demand is an increasing function of the product value $\mathrm{V}$. In this paper, our analysis focuses on $\theta$. The demand, $\theta$, is assumed to be a random variable with a distribution function $\mathrm{F}($.) and mean $\theta 0$.

The supplier and the retailer can exert marketing efforts to embellish the product and manipulate the consumers' beliefs. For example, the supplier may conduct a national advertising campaign to promote the product functions and features or hire public relationship companies to publish 
positive articles at major journals to persuade consumers to buy. The retailer may offer various promotional incentives such as gift with purchase, next purchase discount, or other non-monetary incentives to boost the local demand. Let $\mathrm{x}$ and $\mathrm{y}$ be the supplier's and retailer's marketing efforts respectively. $\mathrm{Cs}(\mathrm{x})$ and $\mathrm{Cr}(\mathrm{y})$ are used to denote the supplier's and the retailer's cost functions respectively. It is assumed that both $\mathrm{Cs}(\mathrm{x})$ and $\mathrm{Cr}(\mathrm{y})$ are increasing and convex functions, i.e., $\mathrm{C}^{\prime} \mathrm{s}(\mathrm{x})>0, \mathrm{C}^{\prime \prime} \mathrm{s}(\mathrm{x})>0, \mathrm{C}^{\prime} \mathrm{r}(\mathrm{y})>0$ and $\mathrm{C}^{\prime \prime} \mathrm{r}(\mathrm{y})>0$. In addition, $\mathrm{Cs}(0)=0, \mathrm{C}^{\prime} \mathrm{s}(0)=0, \mathrm{Cr}(0)=0$ and $\mathrm{C}^{\prime} \mathrm{r}(0)=0$. These assumptions ensure the existence of unique interior solutions. In this paper, it is assumed that neither the supplier nor the retailer can observe the other party's marketing effort, which yields a double moral hazard problem in the supply chain [2]. The consumers cannot observe any marketing efforts.

A direct consequence of successful marketing campaigns is higher market demand. We use d to denote the market demand of the product and assume that in period $\mathrm{t}, \mathrm{dt}$ is dependent on $\theta$ (refereed to as the base demand in the rest of the paper), the supplier's marketing effort, $\mathrm{xt}$, and the retailer's marketing effort, yt. In particular,

$$
d_{t}=\theta+x_{\mathrm{t}}+y_{t}+\varepsilon
$$

where $\varepsilon t$ is a random error representing unobservable market fluctuations. We assume that $\varepsilon t$ is a random variable with the distribution function $\mathrm{G}($.$) and mean 0$.

The supplier and the retailer have complete information on the number of products sold in the supply chain. As we discussed in the Introduction, the product sales are often public information in the consumer market. We therefore assume that the market demand $\mathrm{dt}$ is observable and verifiable. However no one observes the base demand $\theta$ (or the true product value V). Since the demand, dt, carries information about the base demand $\theta$ (or the product value V), potential consumers can learn the base demand (or the product value) through their observations of the market demands. Therefore, the market demand dt can be considered as a signal of the base demand $\theta$. The consumers update their beliefs on the based demand $\theta$ (i.e., the product value $\mathrm{V}$ ) based on their observations of market demands $\mathrm{Dt}=\{\mathrm{d} 1, . . \mathrm{dt}\}$.

The sequence of events is as follows. At the beginning of the time horizon, $\theta$ is realized and then the supplier decides the revenue sharing ratio $\phi$. The supplier and the retailer interact for multiple periods. At the beginning of period $\mathrm{t}=2, \ldots, \mathrm{N}$, the consumers observe the product sales in the previous period, $\mathrm{dt}-1$ and update their beliefs on the base demand (or product value). The supplier and the retailer then estimate the market demand taking account of consumer learning. The supplier and retailer decide their marketing efforts, $x t$ and yt. At the end of period $t$, the demand, dt, is realized and the supplier keeps $(1-\phi)$ pdt of the revenue and the retailer obtains $\phi p d t$ of the revenue. We assume everything is common knowledge except the true value of the product value $\theta$, the market fluctuation $\varepsilon$, the supplier effort xt and the retailer's effort yt, $\mathrm{t}=1, \ldots, \mathrm{N}$.

\section{No consumer learning}

We first consider the cases without consumer learning. When there is no consumer learning, the supplier and the retailer's marketing efforts only affect the product sales in the current periods. 
The supplier's (the retailer's) optimization problem is the same in each period. For ease of exposition, we drop the subscript $t$ and focus on analyzing a one-period model in this section. We first consider the case where the supplier and the retailer have symmetric information and then the case where there is asymmetric information between the supplier and the retailer. In the rest of the paper, we use the superscript ij to denote the information structure of the supply chain. In particular, $i \in\{m, a\}$ where $m$ represents symmetric information and a represents asymmetric information; and $j \in\{n, 1\}$ where $n$ represents no consumer learning and 1 represents consumer learning.

\subsection{Symmetric information without consumer learning}

In the case of symmetric information, the firms' marketing efforts are common knowledge, i.e., both firms' efforts are observable and verifiable to each other. The supplier and retailer can directly contract on the marketing efforts. We use $\Pi$ to represent the supplier's profit and $\pi$ to represent the retailer's profit. The superscript $\mathrm{mn}$ represents the case with symmetric information and no consumer learning. In the one-period model, the supplier's optimization problem can be represented by

$$
\begin{aligned}
\Pi^{m n}= & \max _{\phi, x y} E\left[(1-\phi) p d-C_{s}(x)\right] \\
& \text { s.t. } \pi^{m n}=E\left[\phi p d-C_{r}(y)\right] \geq 0 .
\end{aligned}
$$

where (IR) is the retailer's individual rationality constraint which ensures that the retailer's profit is not less than its reservation utility. In this paper, we assume that the retailer's reservation utility is zero. In the case with symmetric information, the IR constraint is binding. We therefore have

$$
\phi=\frac{C_{r}(y)}{p E[d]},
$$

and the supplier chooses the marketing efforts which maximize the total profit

$$
\Pi^{m n}=\max _{x, y} E\left[p d-C_{s}(x)-C_{r}(y)\right] .
$$

Substitute Eq. (1) into (2) and apply $E[\theta]=\theta 0$ and $E[\varepsilon]=0$, we have

$$
\Pi^{m n}=\max _{x, y} p\left(\theta_{0}+x+y\right)-C_{s}(x)-C_{r}(y) .
$$

Using the first-order-conditions, the supplier and the retailer's efforts are given by

$$
C_{r}^{\prime}\left(y^{m n}\right)=p, C_{s}^{\prime}\left(x^{m n}\right)=p
$$


When the supplier has complete information, the supplier can specify the retailer's marketing effort in the contract. $\phi$ is chosen to compensate the retailer's cost of marketing effort. There is no incentive cost under this situation. The supplier will choose the marketing efforts which maximize the total profit of the supply chain. The supplier extracts all the surplus and maximizes the total benefit.

\subsection{Asymmetric information without consumer learning}

In the case of asymmetric information, the marketing efforts are unobservable and the supplier and the retailer cannot directly contract on the marketing efforts. The supplier has to share the revenue to motivate the retailer to exert effort. We use the superscript an to represent the case with asymmetric information and no consumer learning. The supplier and retailer's optimization problems can be represented

$$
\begin{aligned}
& \Pi^{a n}= \max _{\phi, x} E\left[(1-\phi) p d-C_{s}(x)\right], \\
& \text { s.t. } \pi^{a n}=\max _{y} E\left[\phi p d-C_{r}(y)\right] \geq 0
\end{aligned}
$$

and

$$
\pi^{a n}=\max _{y} E\left[\phi p d-C_{r}(y)\right]
$$

The supplier and the retailer's marketing efforts are given by

$$
\begin{aligned}
& C_{s}^{\prime}\left(x^{a n}\right)=(1-\phi) p, \\
& C_{r}^{\prime}\left(y^{a n}\right)=\phi p .
\end{aligned}
$$

Since $C^{\prime \prime}{ }_{s}(x)>0, C^{\prime \prime}{ }_{r}(y)>0$, we have $x^{a n}<x^{m n}$ and $y^{a n}<y^{m n}$ as long as $0<\phi<1$. Based on Eqs. (4) and (5), $\phi$ can be represented by

$$
\phi=\frac{C_{r}^{\prime}\left(y^{a n}\right)}{C_{s}^{\prime}\left(x^{a n}\right)+C_{r}^{\prime}\left(y^{a n}\right)} .
$$

Eq. (6) gives the relationship between the revenue sharing ratio and the firms' marketing efforts. It essentially requires that the supplier and retailer choose their marketing efforts so that the ratio of the retailer's marginal marketing cost to the total of marginal marketing costs is equal to the revenue sharing ratio. The revenue sharing ratio imposes a constraint on the supplier and the retailer's marketing efforts. The supplier chooses the revenue sharing ratio to maximize its profit subject to this constraint. The interior solution of $\phi$ is given by 


$$
\phi^{a n}=1-\frac{\left(\theta_{0}+y^{a n}+x^{a n}\right)}{\frac{\partial y^{a n}}{\partial \phi}} .
$$

From Eq. (5), we have $\frac{\partial y^{\oplus n}}{\partial \phi}=\frac{p}{C_{r}\left(v^{\oplus n}\right)^{\prime}}$ Therefore,

$$
\phi^{a n}=1-C_{r}^{\prime \prime}\left(y^{a n}\right) \frac{\left(\theta_{0}+y^{a n}+x^{a n}\right)}{p} .
$$

The supplier shares the revenue with the retailer to provide the retailer with incentives to exert marketing effort. A positive proportion of revenue is shared only when the retailer's marketing effort is not very costly. When $\mathrm{C}^{\prime \prime} \mathrm{r}(\mathrm{y})$ is very high, it is too costly for the supplier to motivate the retailer. As a result, the supplier chooses to set $\phi=0$ and keeps all the revenue.

\subsection{Numerical example}

We use a numerical example to illustrate the firms' marketing strategies in the cases without consumer learning. We assume that the distribution function for the base demand $\theta$ is $N\left(\theta_{0}, \sigma_{\theta}^{2}\right)$ [17] and the distribution function for the random error $\varepsilon$ is $N\left(0, O_{\varepsilon}^{2}\right)$. Let $\sigma_{\theta}^{2}=0.8, \sigma_{\varepsilon}^{2}=0.5, \theta=0.5, p=1, C_{s}(x)=\frac{1}{2} x^{3}, C_{r}(y)=\frac{1}{10} y^{3}$ and $N=20$. The retailer cost is assumed to be much smaller than the supplier's cost to ensure that the supplier will share a positive proportion of revenue with the retailer. These specifications will be used throughout the paper. We first consider the case with symmetric information. Based on the results in Section 4.1, we have $x^{m n}=0.82$ and $y^{m n}=1.83$. We then consider the case with asymmetric information. Based on the results in Section 4.2, we have $x^{a n}=0.75, y^{a n}=0.71$ and $\phi^{a n}=0.154$. Comparing $x^{m n}$ and $x^{a n}, y^{m n}$ and $y^{a n}$, we can conclude that the firms' marketing effort in the asymmetric case is less than those in the symmetric case. These results are consistent with the literature on moral hazard [6].

\section{Consumer learning}

In this section, we examine the cases with consumer learning. We first consider the case where the supplier and retailer have symmetric information and then the case where there is information asymmetry between the supplier and the retailer. The consumers are uncertain about the true value of the product but they can learn the product value through prior product sales. In particular, at the beginning of period $t$, the consumers observe the historical product sales till period $t-1$ and update their beliefs on the product value. Then the consumers make their purchase decisions. The product sales are considered as signals of the base demand.

\subsection{Modeling consumer learning}


Let $D_{t-1}=\left(d_{1}, d_{2}, \ldots, d_{t-1}\right)$ represent the history of the product sales in the previous $t-1$ periods. $E\left[\theta \mid D_{t-1}\right]$ represents the consumers' expectation of $\theta$ after observing $\mathrm{D}_{t}-1$. Whten $t=1$, $\mathrm{E}[\theta \mid \mathrm{D} 0]=\theta_{0}$. When $t>1$, based on Eq. (1), the base demand can be represented by

$$
\theta+\varepsilon=d_{t}-y_{t}-x_{t}
$$

For tractability, we assume that both the base demand $\theta$ and the random error $\varepsilon$ are normally distribution with distribution functions $N\left(\theta_{0}, \sigma_{\theta}^{2}\right)$ and $N\left(0, \sigma_{\varepsilon}^{2}\right)$ respectively. We let $\sigma_{\theta}^{2}>\sigma_{\varepsilon}^{2}$. According to normal learning theory, at the beginning of period $t$, the posterior distribution of $\theta$ conditional on the prior product sales $\mathrm{D}_{t}-{ }_{1}$ is still a normal distribution with the mean $\mathrm{E}\left[\theta \mid \mathrm{D}_{t}-1\right]$ and the variance $\sigma_{\theta_{t}}^{2}$ where $\mathrm{E}\left[\theta \mid \mathrm{D}_{t}-1\right]$ and $\sigma_{\theta_{t}}^{2}$ are given by

$$
\begin{aligned}
& E\left[\theta \mid D_{t-1}\right]=\left(1-\tau_{t}\right) E\left[\theta\left[D_{t-2}\right]+\tau_{t}\left(d_{t-1}-\bar{y}_{t-1}-\bar{x}_{t-1}\right) .\right. \\
& \frac{1}{\sigma_{\theta_{t}}^{2}}=\frac{1}{\sigma_{\theta_{t-1}}^{2}}+\frac{1}{\sigma_{\varepsilon}^{2}}=\frac{1}{\sigma_{\theta}^{2}}+(t-1) \frac{1}{\sigma_{\varepsilon}^{2}} .
\end{aligned}
$$

$\bar{x}_{t-1}$ and $\bar{y}_{t-1}$ are the consumers' expectations of the supplier and retailer's equilibrium marketing efforts in period $t-1$. Since the consumers cannot observe the marketing efforts, $x_{t-1}$ or $y_{t-1}$, the learning process depends on the consumers expectations, $\bar{x}_{t-1}$ and $\bar{y}_{t-1 \text {. }}$ $E\left[\theta \mid D_{t-1}\right]$ represents the consumers' updated beliefs of the base demand. It is a weighted average of the prior belief of the base demand, $E\left[\theta \mid D_{t-2}\right]$, and the signal, $d_{t-1}-\bar{x}_{t-1}-\bar{y}_{t-1} \cdot \tau_{t} \in[0,1]$ determines the weights the consumers allocate to the prior belief and the signal. We refer to $\tau t$ as the learning factor in the rest of the paper. Based on normal learning theory, the learning factor $\tau t$ is given by

$$
\tau_{t}=\frac{\sigma_{\theta_{t-1}}^{2}}{\sigma_{\theta_{t-1}}^{2}+\sigma_{\varepsilon}^{2}}, t=2, . . N
$$

where $\sigma_{\theta_{t-1}^{2}}$ is the variance of the consumers' belief on the base demand $\theta$ in period $t-1$.

Lemmas 1 and 2 characterize the sequence of $\tau_{t}, t=1 . .^{\infty}$. All proofs are provided in Appendix A.

Lemma 1. The learning factor $\tau_{t}\left(t=1 . .{ }^{\infty}\right)$ is decreasing in $\sigma_{\varepsilon}^{2}$ and $t$, and increasing in $\sigma_{\theta}^{2}$.

The variance of the consumers' belief on the base demand in time period $t, \sigma_{\theta}^{2} \cdot$, decreases as $t$ increases. When $t \rightarrow \infty, \sigma_{\theta}{ }^{2}=0$ The learning process is a random walk with the variance that 
declines deterministically to zero [14]. The learning factor is also decreasing in t, i.e., $\frac{\partial \tau_{t}}{\partial t}<0$. That is, when the prior belief of the product demand is more random, the learning factor is larger. These suggest that when the signals are more informative, the market learns more from the product sales. The learning process speeds up with higher quality signals and/or more random prior belief. Lemma 2 characterizes an important property the learning factors. This property will be used to derive the firms' equilibrium strategies.

Lemma 2. The sequence of $\tau_{t}(t=2 . . N)$ satisfies the following condition,

$$
\tau_{t+1}=\frac{\tau_{t}}{1+\tau_{t}}
$$

This section analyzes the impact of consumer learning on the firms' marketing efforts and revenue sharing strategy. Consumer learning influences the firms' decisions because the firms' beliefs of the product demand depend on the consumers' beliefs. As the consumers learn more information and update their beliefs on the product value, the firms also update their beliefs on the base demand. Therefore, Eq. (7) also represents the supplier and the retailer's expectations on the base demand. As we will show later, the supplier and the retailer's marketing efforts in a period has a long-term effect because of consumer learning.

Since the marketing efforts are unobservable, we use the concept of rational expectations equilibrium (REE) to derive the solution [14,20]. A REE of our model satisfies the following conditions: (1) given the consumers' expectations of the firms' marketing efforts and the prior product sales, the consumers update their beliefs on the product value and the firms update their beliefs on the base demand; (2) given the supplier's expectations of the retailer's marketing efforts in the previous periods, the supplier decides its effort level; (3) given the retailer's expectations of the supplier's efforts in the previous periods, the retailer decides its effort level; (4) the consumers and firms' expectations are consistent with equilibrium values.

\subsection{Symmetric information with consumer learning}

We first consider the case with symmetric information and consumer learning in this section. In the case with symmetric information, the firm's marketing efforts are observable and verifiable. The firms therefore can enforce a long-term contract on the revenue sharing ratio and marketing efforts. Since the revenue sharing is a long term strategic decision, it should be decided at the beginning of the time horizon. Consumer learning occurs at the beginning of each period, consumers learn the product value through their observations of the product sales in the previous periods. The supplier and retailer update their beliefs of the base demand taking account of consumer learning. In Section 5.2, the supplier is assumed to decide the supplier and the retailer's marketing efforts at the beginning of the time horizon. Alternatively, we can examine the case that the supplier decides the marketing efforts at the beginning of each period after it observes the product sale in the previous period. The solutions of these two problems are the same. We use the superscript $m l$ to denote the case with symmetric information and consumer learning. We consider the case where the retailer and supplier interact for multiple $(\mathrm{N} \geq 2)$ periods. Recall that 
$D_{t-1}=\left(d_{1}, d_{2}, \ldots, d_{t-1}\right)$ represents the history of product sales in the previous $\mathrm{t}-1$ periods. The supplier's optimization problem can be represented as

$$
\begin{aligned}
\Pi^{m l}= & \max _{\phi, x_{t} y_{t}} \sum_{t=1}^{N} E\left[(1-\phi) p d_{t}-C_{s}\left(x_{t}\right) \mid D_{t-1}\right] \\
& \text { s.t. } \pi^{m l}=\sum_{t=1}^{N} E\left[\phi p d_{t}-C_{r}\left(y_{t}\right) \mid D_{t-1}\right] \geq 0 .
\end{aligned}
$$

The (IR) constraint requires that the supplier will choose a $\phi$ to ensure the retailer's total expected profit is greater than zero. Since the supplier has complete information (i.e., it can observe and verify the retailer's efforts), it specifies the retailer's marketing efforts in the contract. The supplier's payment is used to cover the retailer's total cost of marketing efforts. There is no incentive cost in this case. We therefore have $\pi_{t}^{m l}=\sum_{t=1}^{N} E\left[\phi p d_{t}-C_{r}\left(y_{t}\right) \mid D_{t-1}\right]=0$. The supplier determines the marketing efforts by maximizing the total profit of the supply chain. The supplier's optimization can be written as

$$
\Pi_{t}^{m l}=\max _{\phi, x_{t}, y_{t}} \sum_{t=1}^{N} E\left[p d_{t}-C_{s}\left(x_{t}\right)-C_{r}\left(y_{t}\right) \mid D_{t-1}\right]
$$

The marginal profit of the marketing efforts are

$$
\begin{aligned}
& \frac{\partial \prod^{m l}}{\partial x_{t}}=\sum_{i=0}^{N-t}\left(p \frac{\partial E\left[d_{t+i} \mid D_{t+i-1}\right]}{\partial x_{t}}-C_{s}^{\prime}\left(x_{t}\right)\right), \\
& \frac{\partial \prod^{m l}}{\partial y_{t}}=\sum_{i=0}^{N-t}\left(p \frac{\partial E\left[d_{t+i} \mid D_{t+i-1}\right]}{\partial x_{t}}-C_{r}^{\prime}\left(y_{t}\right)\right) .
\end{aligned}
$$

Lemma 3 provides the relationships between the firms' marketing efforts and the market demand.

Lemma 3. The relationships between the firms' marketing efforts and the market demand are as follows.

1. $\frac{\left.\partial E d_{t} t D_{t-1}\right]}{\partial x_{t}}=1$ and $\frac{\partial E\left[d_{t} \mid D_{t-1}\right]}{\partial y_{t}}=1$.

2. $\frac{\left.\partial E d_{t, i} \mid D_{t i-1}\right]}{\partial x_{t}}=\tau_{t+i}$ and $\frac{\left.\partial E d_{t, j} \mid D_{t+i-1}\right]}{\partial y_{t}}=\tau_{t+i}, i=1 . . N-t$.

3. $\frac{\partial E\left[d_{t} \mid D_{t-1}\right]}{\partial x_{t}}>\frac{\partial E\left[d_{t, j} \mid D_{t+i-1}\right]}{\partial x_{t}}, \frac{\partial E\left[d_{t} \mid D_{t-1}\right]}{\partial y_{t}}>\frac{\partial E\left[d_{t+i} \mid D_{t+i-1}\right]}{\partial y_{t}}, i=1 \ldots N-t, t=1 . . N-1$.

The firms' marketing efforts in period $t$ influence not only the market demands in period $t$ but those in the future periods. The impact of the firms' marketing efforts on the market demands is 
determined by the learning factors $\tau \mathrm{t}(\mathrm{t}=1 \ldots \mathrm{N})$. Lemma 3 shows that $\tau \mathrm{t}$ is decreasing in $\mathrm{t}$. This declining sequence implies that the marketing efforts $x_{t}$ and $y_{t}$ in period thas a higher impact on the recent demands than on the future demands.

Proposition 1 gives the firms' marketing efforts in the case with symmetric information and consumer learning.

Proposition 1. 1. When $t<N$, we have

$$
\begin{aligned}
& C_{s}^{\prime}\left(x_{t}^{m l}\right)=p\left(1+\sum_{i=1}^{N-t} \tau_{t+i}\right), \\
& C_{r}^{\prime}\left(y_{t}^{m l}\right)=p\left(1+\sum_{i=1}^{N-t} \tau_{t+i}\right) .
\end{aligned}
$$

When $t=N$, we have

$$
C_{s}^{\prime}\left(x_{N}^{m l}\right)=p, C_{r}^{\prime}\left(y_{N}^{m l}\right)=p .
$$

2. The supplier's and retailer's marketing efforts are decreasing from the initial time period though time period $t$.

3. The supplier and retailer's marketing efforts are higher than those in the case with symmetric information and no consumer learning.

In period $\mathrm{N}$, the firms' marketing efforts are the same as those in the case with symmetric information and no consumer learning. This is because period $N$ is the last period and there is no consumer learning any more. The firms' marketing efforts in period $N$ only influence the consumer demand and the supply chain's profit in this period. When $t<N$, Lemma 3 shows that the firms' marketing efforts in period $t$ also influence the market demands thereafter, i.e., $d_{t}+1 . . d_{N}$. Eqs. (8) and (9) show that the supplier considers the aggregate impact of the marketing efforts on the market demands when deciding the effort levels.

Proposition 1.2 and 1.3 further characterize the firms's marketing efforts in the case with symmetric information and consumer learning. The firms' marketing efforts in an earlier period impact the market demands for a longer period than those in a later period. As $t$ increases, the expression $1+\sum_{i=1}^{N-t} \tau_{t+i}$ has less terms. Therefore, $1+\sum_{i=1}^{N-t} \tau_{t+i}$ is a decreasing function of $t$. Since $\mathrm{Cs}($.$) and \mathrm{Cr}($.$) are increasing and convex functions, the firms' marketing efforts are higher in an$ earlier period than those in a later period. The firms' marketing efforts are higher than those in the case with symmetric information and no consumer learning, i.e., $x^{m n}<x_{t}^{m l}$ and $y^{m n}<y_{t}^{m l}$, when $\mathrm{t}<\mathrm{N}$. Why firms have incentives to exert higher efforts in the case with consumer learning? This is because the consumers do not observe the firms' marketing efforts. Lemma 3 shows that 
the firms' marketing efforts have the intertemperal effects. The firms' marketing efforts not only directly affect the demand in the current period but also affect the firms' expectations of the base demand (the consumers' expectation on the true product value). In particular, the term $\sum_{i=1}^{N-t} \tau_{t+i}$ represents the long-term impact of the marketing efforts on the consumers' beliefs. The supplier therefore has a incentive to choose higher marketing efforts to mislead the consumers. It is worth noting that the supplier cannot fool the consumers in the REE. The consumers rationally expect the firms' marketing efforts and adjust their beliefs on the base demand. The consumers take the firms' marketing manipulations into account when updating their beliefs. Consequently the supplier has to make more marketing efforts to compensate the consumers' discounts on their marketing efforts. The supplier demands too much marketing efforts in the case with symmetric information and consumer learning. The social optimal solutions of marketing efforts are given by

$$
C_{s}^{\prime}\left(x_{t}\right)=p, C_{r}^{\prime}\left(y_{t}\right)=p,
$$

Which are the same as the solutions in the case with symmetric information and no consumer learning.

\subsection{Asymmetric information with consumer learning}

This section considers the case where the supplier and the retailer have asymmetric information. At the beginning of the time horizon, the supplier decides the revenue sharing ratio, $\phi$. In contrast to the case with symmetric information, the firms cannot contract on the marketing efforts. In each period, consumers learn the product value through their observations of the product sales in the previous periods. The supplier and retailer update their beliefs of the base demand taking account of consumer learning and decide their marketing efforts. Then the consumers purchase the products. We use the superscript $a l$ to denote the case with asymmetric information and consumer learning. The optimization problems of the supplier and the retailer in time period $t$ are represented by 


$$
\begin{aligned}
& \prod_{t}^{a l}= \max _{x_{t}} \sum_{i=0}^{N-t} E\left[(1-\phi) p d_{t+i}-C_{s}\left(x_{t+i}\right) \mid D_{t+i-1}\right] \\
& \text { s.t. } \pi_{t}^{a l}=\sum_{i=0}^{N-t} E\left[\phi p d_{t+i}-C_{r}\left(y_{t+i}\right) \mid D_{t+i-1}\right] .(\text { IR })
\end{aligned}
$$

and

$$
\pi_{t}^{a l}=\max _{y_{t}} \sum_{i=0}^{N-t} E\left[\phi p d_{t+i}-C_{r}\left(y_{t+i}\right) \mid D_{t+i-1}\right] .
$$

The marginal impact of the firms' efforts are

$$
\begin{gathered}
\frac{\partial \prod_{t}^{a l}}{\partial x_{t}}=\sum_{i=0}^{N-t}(1-\phi) p\left(\frac{\partial E\left[d_{t+i} \mid D_{t+i-1}\right]}{\partial x_{t}}\right)-C_{s}^{\prime}\left(x_{t}\right), \\
\frac{\partial \pi_{t}^{a l}}{\partial y_{t}}=\sum_{i=0}^{N-t} \phi p\left(\frac{\partial E\left[d_{t+i} \mid D_{t+i-1}\right]}{\partial y_{t}}\right)-C_{r}^{\prime}\left(y_{t}\right) .
\end{gathered}
$$

Proposition 2 gives the firms' marketing efforts in the case with asymmetric information and consumer learning.

\section{Proposition 2.}

$$
\begin{aligned}
& C_{s}^{\prime}\left(x_{t}^{a l}\right)=(1-\phi) p\left(1+\sum_{i=1}^{N-t} \tau_{t+i}\right), \\
& C_{r}^{\prime}\left(y_{t}^{a l}\right)=\phi p\left(1+\sum_{i=1}^{N-t} \tau_{t+i}\right), \\
& C_{s}^{\prime}\left(x_{N}^{a l}\right)=(1-\phi) p \\
& C_{r}^{\prime}\left(y_{N}^{a l}\right)=\phi p .
\end{aligned}
$$

We find that the supplier and the retailer's marketing efforts in the period $N$ in the case with asymmetric information and consumer learning are the same as those in the case with asymmetric information and no consumer learning. This is because period $N$ is the last period. The supplier and retailer's marketing efforts have no long-term impact. The firms exert the marketing efforts only for their profits in period $N$. When $t<N$, a firm chooses its marketing effort considering not only the demand in the current period but also the demands in the periods 
thereafter. The marginal cost of the effort is proportional to the total of the learning factors from period $t$ till the end of the time horizon. Proposition 3 gives important properties of the firms' marketing efforts.

\section{Proposition 3.}

1. The supplier's and retailer's marketing efforts are decreasing from the initial time period though time period $t$.

2. The supplier and retailer's marketing efforts are higher than those in the case with asymmetric information and no consumer learning given the same revenue sharing ratio.

3. The supplier and retailer's marketing efforts are less than those in the case with symmetric information and consumer learning.

Proposition 3 shows that the firms' marketing efforts in the earlier periods impact consumer learning for a longer period of time, similar to the case with symmetric information and consumer learning. Therefore, the firms choose higher marketing efforts in the earlier periods than the later periods. The firms' marketing efforts are decreasing in $t$.

Compare the firms' marketing efforts in the cases with asymmetric information, we have $x_{t}^{a l}>x^{a n}$ and $y_{t}^{a l}>y^{a n}$ given a $\phi \in(0,1)$ when $\mathrm{t}<\mathrm{N}$. 1 The increase in market effort is due to the presence of consumer learning. Similar to Proposition 1.2 and 1.3, because of consumer learning, the firms have incentives to exert higher marketing efforts to mislead consumers. In a REE, the consumers rationally expect the firms' manipulation and adjust their belief updating. As a result, the firms have to increase their marketing efforts to compensate the consumers' discount. We also have $x_{t}^{a l}>x^{a n}$ and $y_{t}^{a l}>y^{a n}$ given a $\phi \in(0,1)$. This is due to the issue of double moral hazard. When the supplier and the retailer have asymmetric information, the supplier has to use revenue sharing to motivate the retailer to exert effort. Since the benefits of marketing efforts are split between the supplier and the retailer, both the supplier and retailer's marketing efforts are lower than those in the symmetric case.

The supplier determines the revenue sharing ratio $\phi$ in the first period in consideration of its total profit over $\mathrm{N}$ period. The supplier's optimization problem is

$$
\begin{aligned}
\prod a l= & \max _{\phi} \sum_{t=1}^{N} E\left[(1-\phi) p d_{t}-C_{s}\left(x_{t}\right) \mid D_{t-1}\right] \\
& \text { s.t. } \pi_{t}^{a l}=\sum_{t=1}^{N} E\left[\phi p d_{t}-C_{r}\left(y_{t}\right) \mid D_{t-1}\right] \geq 0 .
\end{aligned}
$$

Proposition 4 gives the optimal revenue sharing ratio in the case with asymmetric information and consumer learning.

\section{Proposition 4.}




$$
\phi^{a l}=1-\frac{\sum_{t=1}^{N}\left(\theta_{0}+y_{t}^{a l}+x_{t}^{a l}\right)}{\sum_{t=1}^{N} \frac{\partial y_{t}^{a l}}{\partial \theta}-\sum_{t=1}^{N-1}\left(\tau_{t+1}\left(\sum_{i=1}^{t} \frac{\partial \alpha_{i}^{l a}}{\partial \theta}\right)\right)}
$$

The term, $\quad-\sum_{t=1}^{N-1}\left(\tau_{t+1}\left(\sum_{i=1}^{t} \frac{\partial x_{i}^{t}}{\partial \phi}\right)\right)$, captures the impact of the consumer learning on the supplier's revenue sharing decision. From Eq. (10), we have $\frac{\partial \alpha_{i}}{\partial \phi}<0$. Therefore, $-\sum_{t=1}^{N-1}\left(\tau_{t+1}\left(\sum_{i=1}^{t} \frac{\partial x_{i}^{t}}{\partial \phi}\right)\right)$ represents a positive impact of consumer learning on $\phi^{a l}$. Proposition 2 shows that the supplier has more incentive to exert marketing effort with consumer learning. Therefore, the negative consequence of revenue sharing (due to moral hazard) on the supplier's marketing effort is alleviated. The supplier is willing to share more revenue with the retailer to motivate retailer exert more effort. To provide a complete picture of the impact of consumer learning on the firms' marketing efforts and revenue sharing strategies, Section 6 illustrates and compares the firms' strategies numerically.

\section{Discussion}

This section compares the firms' marketing effort, revenue sharing ratios and profits in different cases numerically. We use the same specifications of the numerical example used in Section 4. In particular, we ley $\sigma_{\theta}^{2}=0.8, \sigma_{\varepsilon}^{2}=0.5, \theta=0.5, p=1, C_{s}(x) \frac{x^{3}}{2}$, and $C_{r}(y)=\frac{y^{3}}{10}$. In addition, we assume that the supplier and retailer interact for 20 periods, i.e., $N=20$.

Fig. 1 illustrates the supplier and retailer's marketing efforts in four cases respectively. Recall that $m n$ represents the case with symmetric information and no consumer learning; $m l$ represents the case with symmetric information and consumer learning; an represents the case with asymmetric information and no consumer learning; and al represents the case with asymmetric information and consumer learning. For comparison purpose, we use the same revenue ratio, $\phi=0.21$, in the an and al cases in Fig. 1. In the $m n$ and $\mathrm{ml}$ cases, the firms' efforts and profits are independent of $\phi$. Without consumer learning (the $m n$ and $a n$ cases), the firms' efforts are constant over time as the dashed lines illustrate. However, when there is consumer learning (the $\mathrm{ml}$ and al cases), both firms' marketing efforts are decreasing in $\mathrm{t}$ as the solid curves illustrate. Consumer learning motivates firms exert more effort in the earlier periods of cooperation than in the later periods. In the last period, the firms only consider their profits in one period. The firms' marketing efforts in the cases with consumer learning are equal to those in the cases without consumer learning. The dashed lines and solid curves meet at $t=N$.

Firms use a revenue sharing contract to coordinate the supply chain in the cases with asymmetric information. The firms have less incentives to exert marketing efforts due to the issue of double moral hazard. The curves (or lines) for the marketing efforts in the cases with asymmetric information (the an and al cases) are lower than those in the corresponding cases with symmetric 
information (the $m n$ and $m l$ cases). Consumer learning provides a countervailing incentive and helps address the moral hazard issue. The firms' marketing efforts in the case with asymmetric information and consumer learning (the $a l$ case) may be closer to the optimal efforts (i.e., the efforts in the case with symmetric information and no consumer learning). Consumer learning effectively mitigates the adverse consequence of moral hazard. It is worth emphasizing that at the earlier stage of cooperation, the supplier marketing effort may be higher than the optimal effort level. Consumer learning may generate social loss. The firms' marketing efforts in the case with symmetric information and consumer learning (the $m l$ case) manifest this negative effect of consumer learning. In the $\mathrm{ml}$ case, the firms' marketing efforts are always higher than the optimal effort levels (the efforts in the $m n$ case).

Fig. 2 compares the optimal revenue sharing ratios given different $\mathrm{N}$ in the two cases with asymmetric information (the an and al cases). Fig. 2 shows that the revenue sharing ratio in the case with consumer learning (the al case) is always higher than that in the case without consumer learning (the an case) given any $N$. This suggests that the supplier is willing to share more revenue with the retailer when there is consumer learning. The purpose of revenue sharing is to provide retailer with incentives to exert marketing effort. On the other hand, revenue sharing also dampens the supplier's incentive to exert effort. Consumer learning motivates the supplier to exert more marketing effort and mitigates the dampening effect of revenue sharing. Therefore, the supplier is willing to share more revenue to the retailer.

Fig. 2 also shows that the revenue sharing ratio in the case with asymmetric information and consumer learning (the $a l$ case) is always increasing in $N$. This suggests that with consumer learning, the supplier tends to share more revenue with retailer if they cooperate for a longer period. This is because the effort-dampening effect of revenue sharing on the supplier side is weaker when $\mathrm{N}$ increases. As Fig. 1(a) shows, consumer learning drives the supplier to exert too much effort. The supplier's marketing efforts may be even higher than the optimal effort level at the earlier stage of cooperation. As a result, the supplier is willing to share more revenue with the retailer when $\mathrm{N}$ is larger. The supplier leverages double moral hazard to mitigate its overinvestment incentive. 
(a) Supplier's Effort

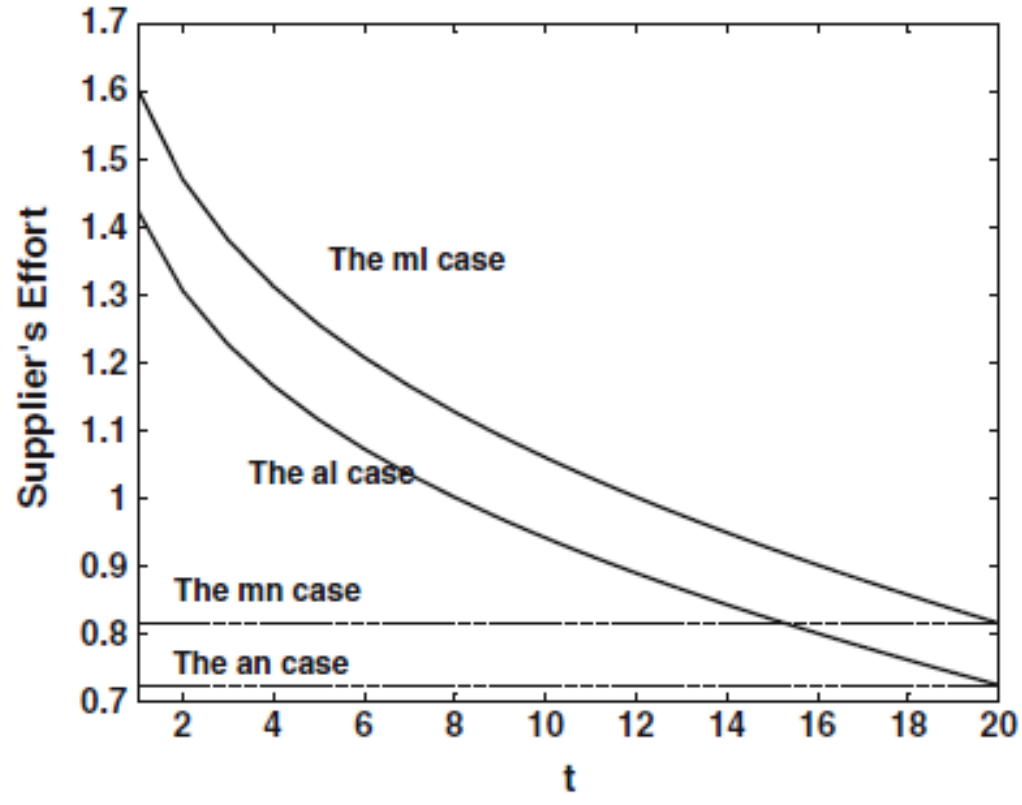

(b) Retailer's Effort

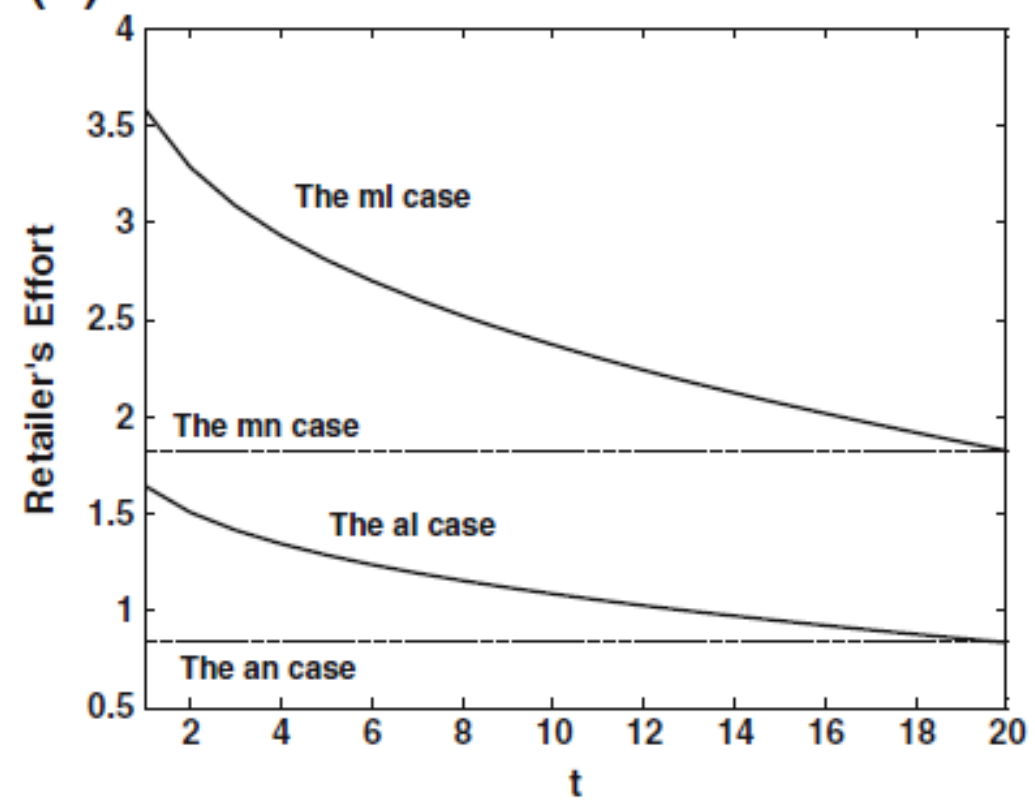

Fig. 1. Firms' efforts in four different case $(N=20$ and $\phi=0.21)$. 


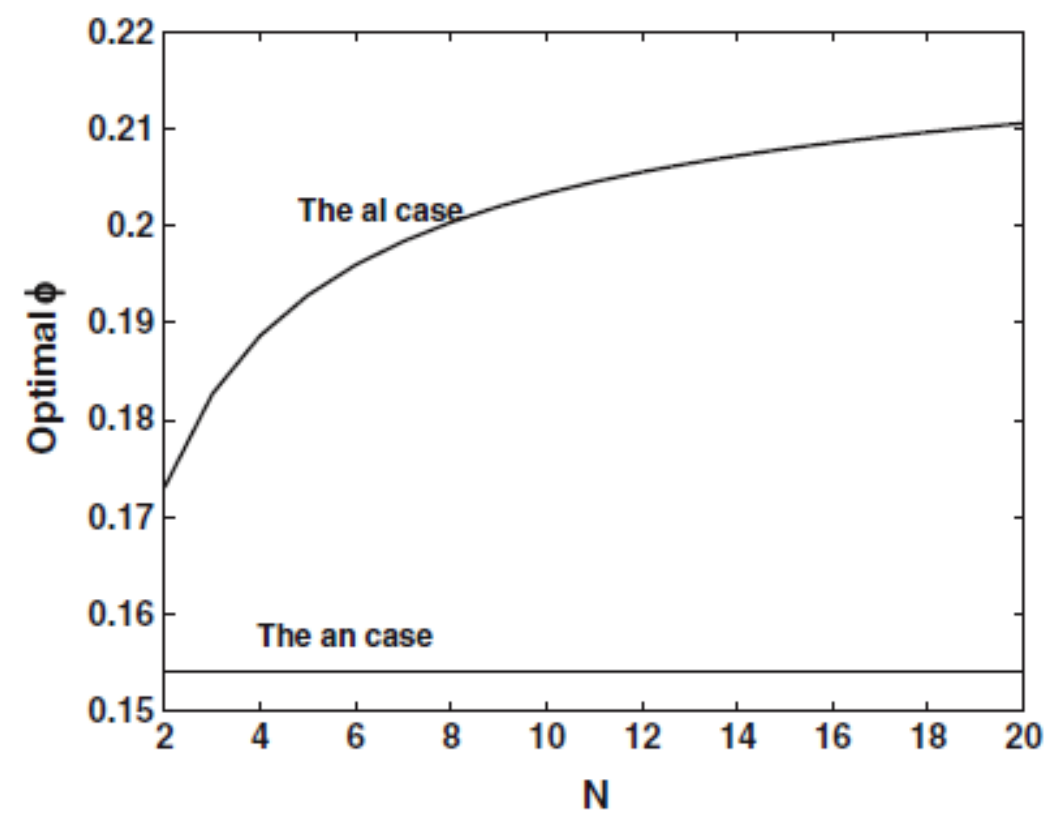

Fig. 2. Optimal $\phi$ given different $N$ in the cases with asymmetric information. 
(a) Supplier's Profit

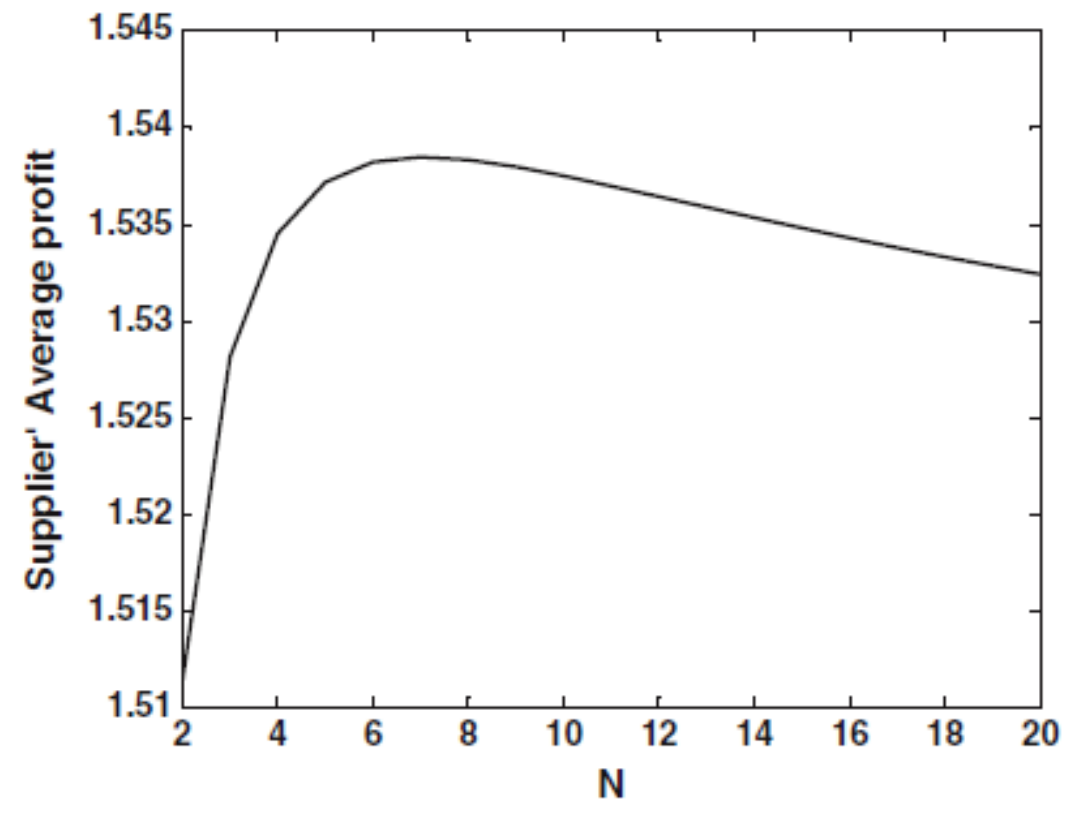

(b) Retailer's Profit

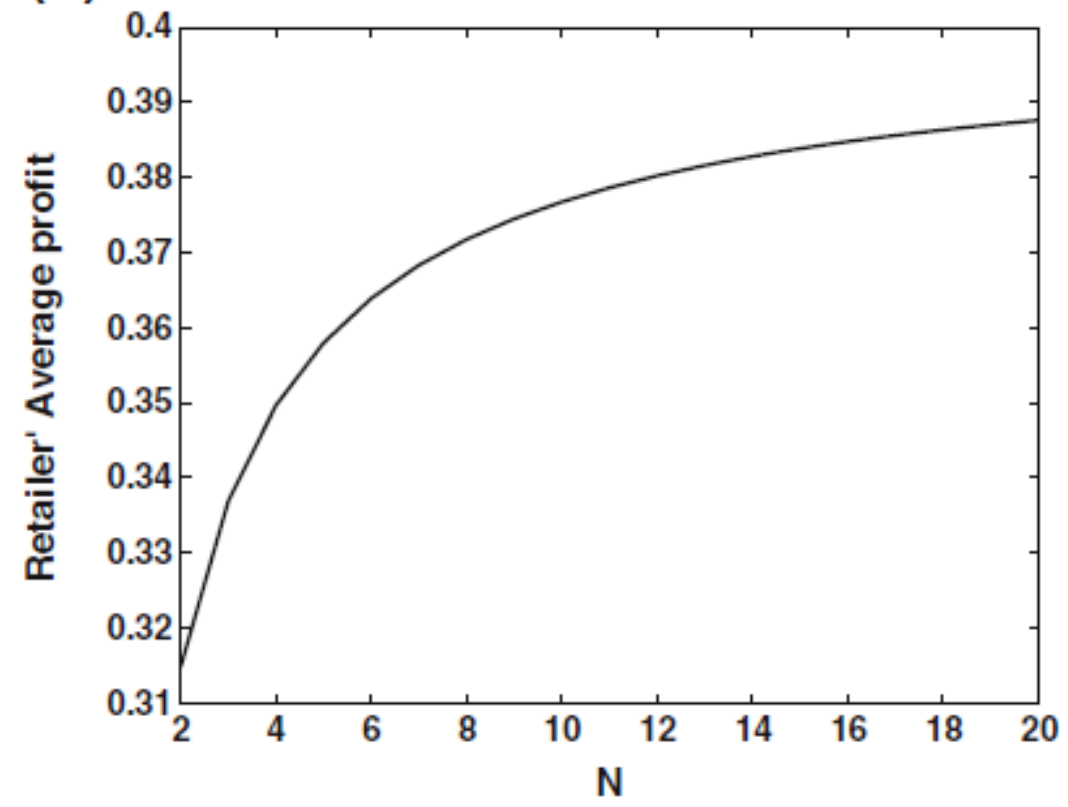

Fig. 3. Firms' average profits given different $N$ (the al case). 
(a) $\mathrm{N}=2 \ldots 20$

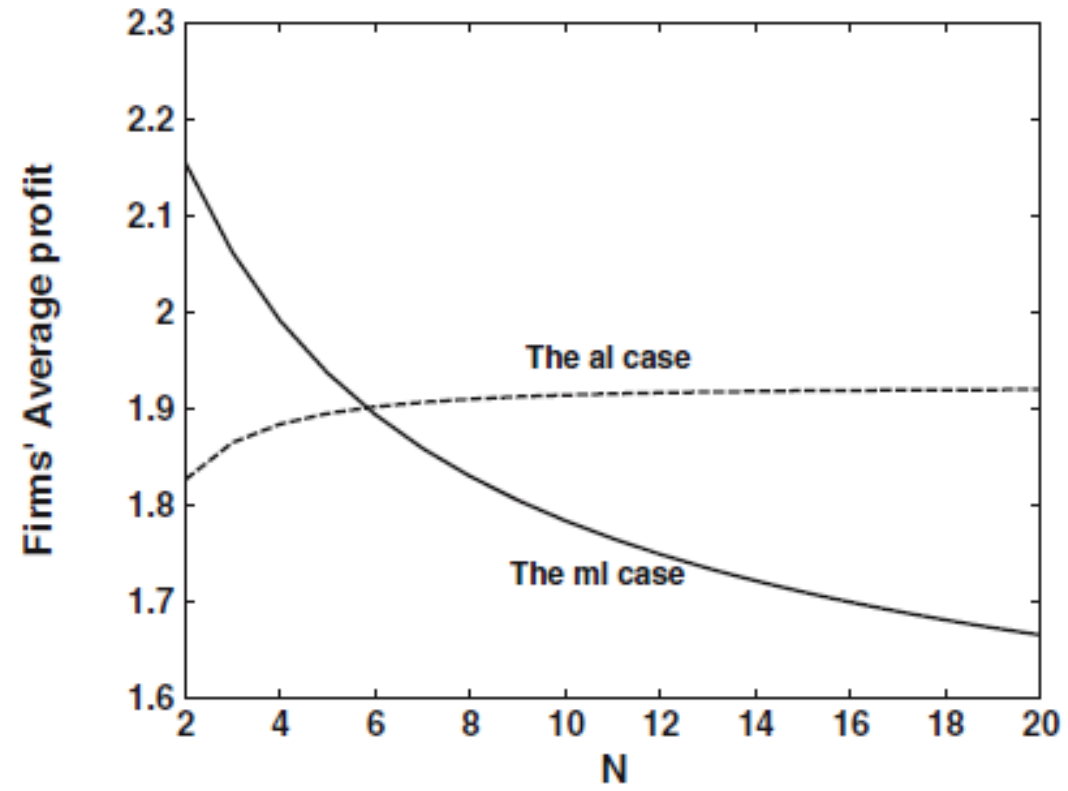

(b) $\mathrm{N}=5 \ldots . .50$

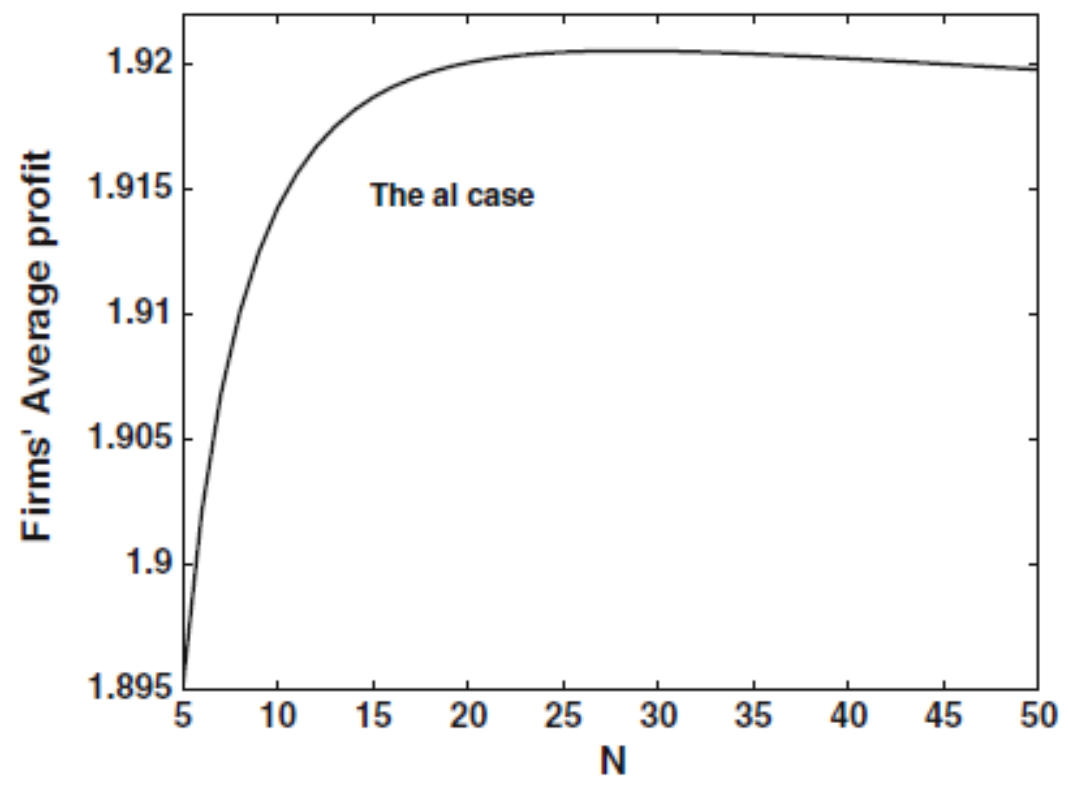

Fig. 4. Firms' average total profit given different $N$ in the case with consumer learning 


\section{(a) Supplier's Effort}

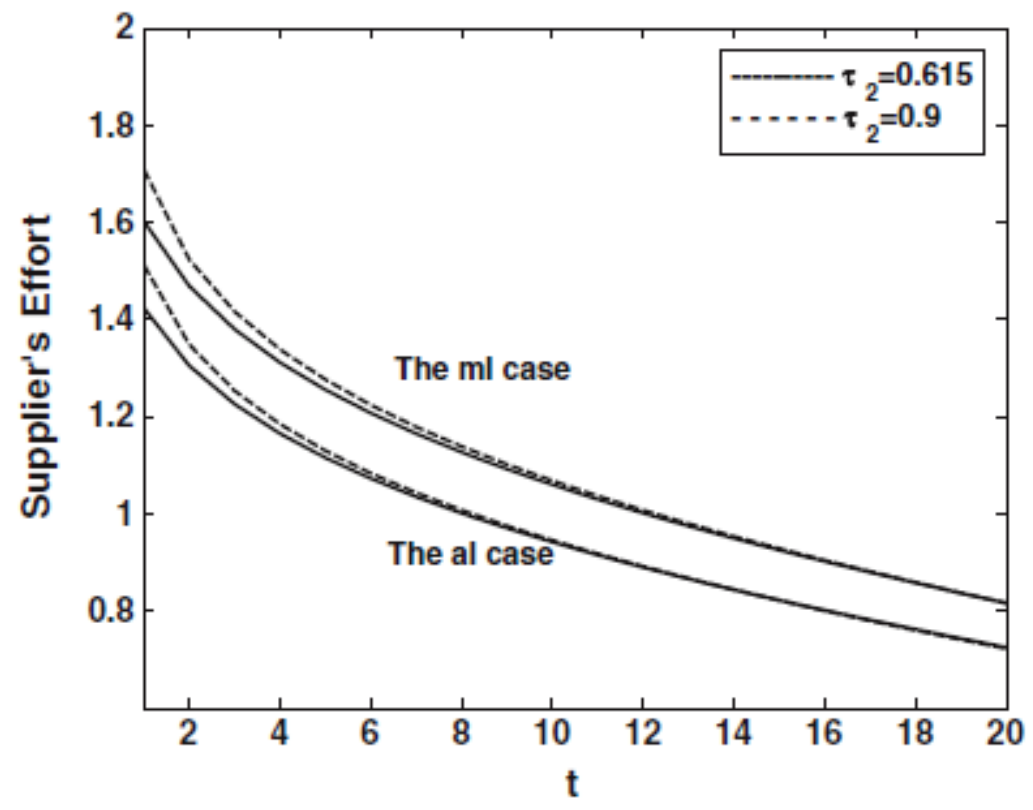

(b) Retailer's Effort

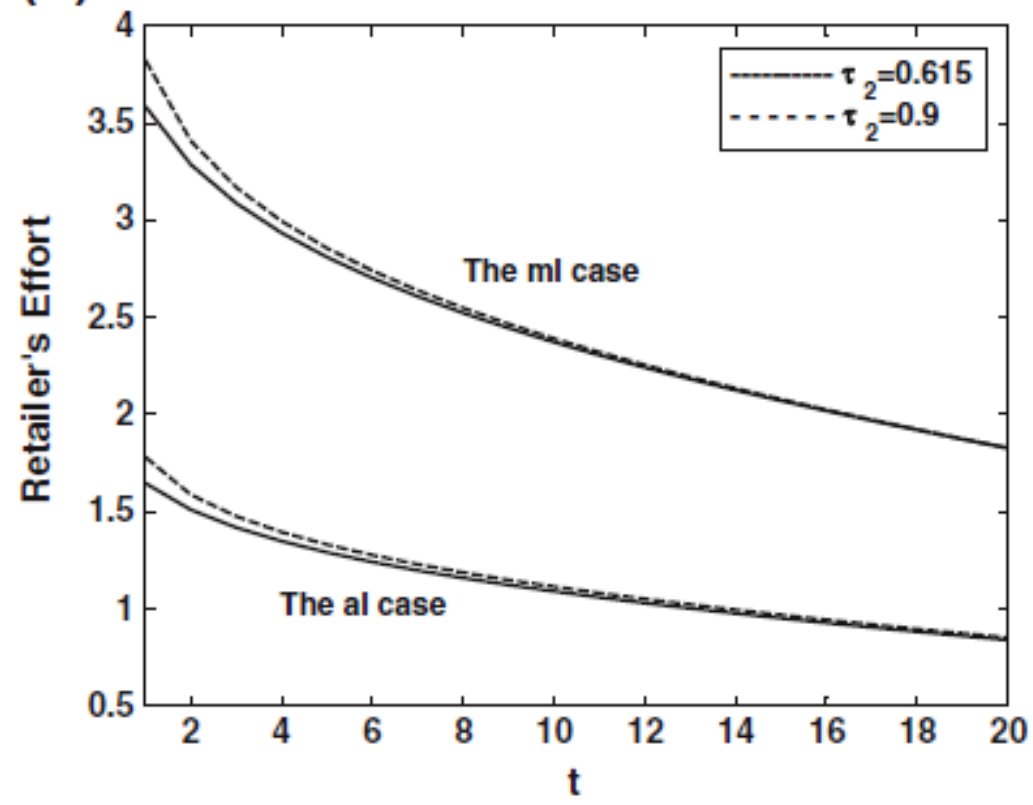

Fig. 5. Firms' efforts in the case with consumer learning $(N=20)$.

Fig. 3 shows the supplier's and retailer's average profits over $N$ periods given different $N$ in the case with asymmetric information and consumer learning (the $a l$ case). We calculate the supplier's (or retailer's) average profit by dividing the supplier's (or retailer's) total expected profit over $N$ period by $N$. We find that the supplier's average profit is first increasing and then decreasing in $N$ but the retailer's average profit is always increasing in $N$. When $N$ is larger, consumer learning induces higher marketing efforts. This helps mitigate the loss due to double 
moral hazard. Therefore, the supplier's profit is first increasing. On the other hand, consumer learning may lead to too much effort on the supplier side, which negatively impacts the supplier's profit. This is why the supplier's profit is decreasing when $N$ is large enough. Why is the retailer's profits always increasing as $N$ increases? This is because the supplier shares more revenue with the retailer when $N$ is larger, which benefits the retailer.

We next examine the role of information in the supply chain with consumer learning. Fig. 4 illustrates the average total profit of the supply chain over $N$ periods given different $N$ in the two cases with consumer learning (the $m l$ and al cases). We calculate the average total profit of the supply chain by dividing total expected profit of the supply chain over $N$ period by $N$. Fig. 4(a) shows that the average total profit of the supply chain is decreasing in $N$ in the case with symmetric information and consumer learning (the $m l$ case) but is increasing in $N$ in the case with asymmetric information and consumer learning (the al case). When the firms cooperate for a longer period of time, the supplier has more incentive to exert marketing efforts to manipulate consumer learning. As a result, the firms exert too much marketing efforts in the case of symmetric information (the $m l$ case) and the social loss is larger. The average total profit of the supply chain is decreasing in $N$. When there is asymmetric information, the supplier can use the revenue sharing ratio to control the levels of marketing efforts. Therefore, the average total profit of the supply chain is higher when $N$ increases (the al case). It is worth noting that the average total profit in the case with asymmetric information and consumer learning (the al case) will eventually dropping as $N$ is getting too large and the effort-enhancing effect of consumer learning is too strong. Fig. 4(b) shows that the average total profit in the al case starts decreasing when $N>28$.

Fig. 4 shows that the average total profit in the case with asymmetric information (the al case) is higher than that in the case with symmetric information (the ml case) when $\mathrm{N}>6$. This finding implies that information asymmetry in the supply chain may be beneficial in presence of consumer learning. When consumers can rationally expect the firms' behaviors, they always discount their observations when making inferences about the product value. Firms have no choice but exert more marketing efforts. Firms' manipulative efforts are in vain except burning money. This yields a situation of the "rat race". Double moral hazard can be leveraged to control firms' incentive of misleading the market and create a better market environment.

We also examine the robustness of our results. Recall that consumer learning is more effective given larger consumer learning factors $\tau_{t}$. Lemma 1 suggests that ${ }^{t}{ }_{t}$ is increasing in the variance of the base demand $\sigma_{\theta}^{2}$ and decreasing in the variance of the market volatility $\sigma_{\varepsilon}^{2}$. We can use the learning factor to represent the impact of both variances. Figs. 5 through 8 show the firms' marketing efforts, the revenue sharing ratios, the firms' average profits, and the average total profits of the supply chain respectively given a sequence of learning factors with $\tau_{2}=\frac{0.8}{0.8+0.5}=0.615$ (depicted with solid lines) and a sequence of learning factor with $\tau_{2}=\frac{0.9}{0.9+0.1}=0.9$ (shown with dashed lines). We find that the curves follow the same patterns as we discussed before.

When the learning factor is higher, the firms' marketing efforts are larger and the revenue sharing factor is larger. Larger learning factors have mixed impacts on the supplier's profit. When $N$ is 
small, consumer learning is desirable, the supplier's profit is higher with larger learning factors. However, when $N$ is large, consumer learning is so strong that the supplier's profit drops earlier given larger learning factors. This is consistent with our discussion about the negative effect of consumer learning. The retailer's profit is always higher with larger learning factors. Higher learning factors also lead to a higher average total profit of the supply chain when $N$ is small but a lower average total profit when $N$ is large in the case with asymmetric information and consumer learning (the $a l$ case). This is because the consumer learning process speeds up when the learning factors are higher. The negative impact of consumer learning also manifests earlier. As Fig. 8(b) shows, the average total profit drops earlier when learning factors are larger. In particular, the average total profit starts decreasing at $\mathrm{N}=28$ when $\tau 2=0.615$ compared to $N=18$ when $\tau 2=0.9$. 
(a) Supplier's Profit

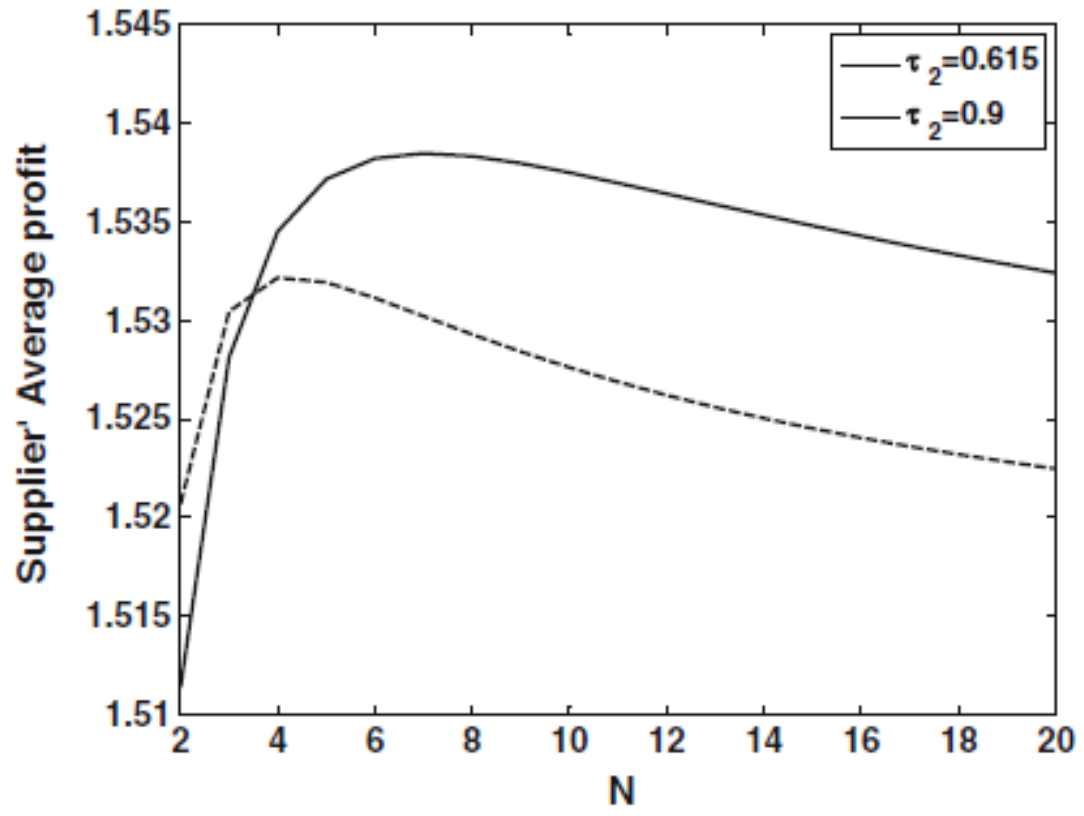

(b) Retailer's Profit

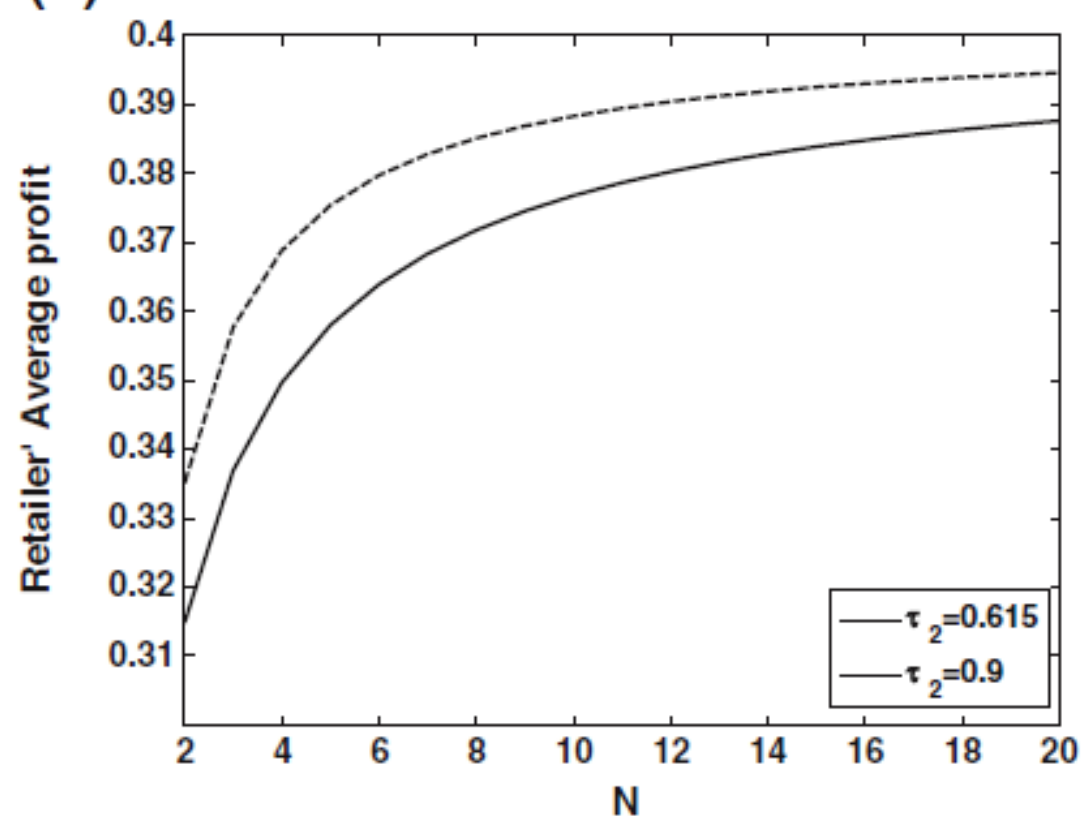

Fig. 7. Firms' average profits given different $N$ (the al case). 


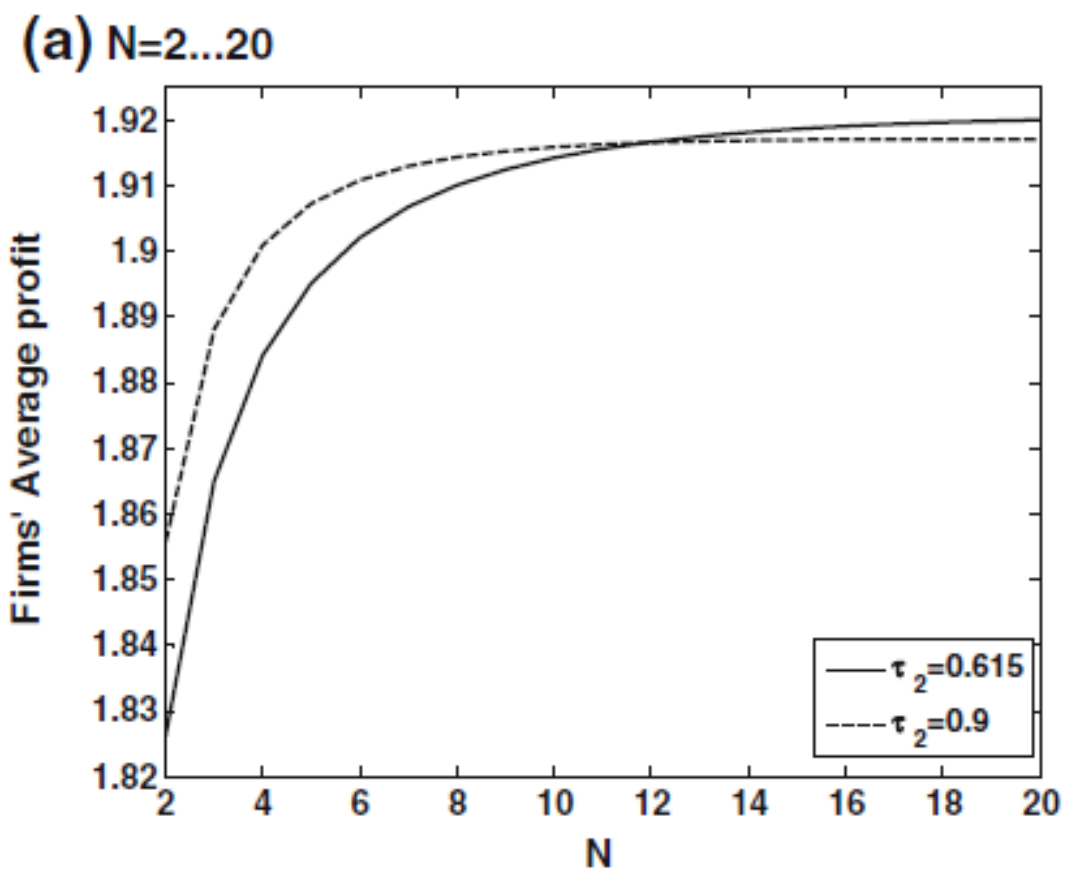

(b) $\mathrm{N}=5 \ldots 100$

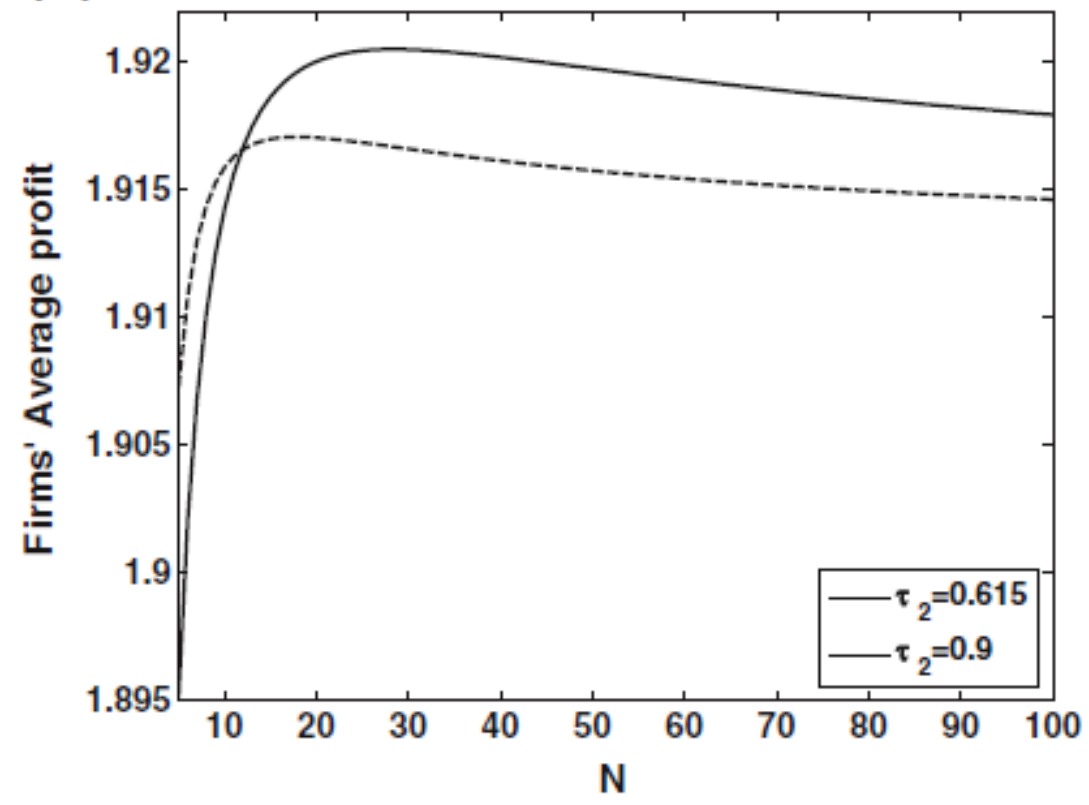

Fig. 8. Firms' average total profit given different $N$ (the al case).

\section{Conclusion}

This paper considers a supply chain with a supplier and a retailer selling to consumers who cannot predict the value of the product with certainty. The consumers learn more about the product and better estimate the product value over time. The supplier and retailer can exert marketing efforts to improve the product sales. We develop a multi-period game-theoretical 
model to study the impact of consumer learning on the firms' marketing strategies and profits in the supply chain and use the REE concept to analyze the model.

We find that the firms exert more marketing efforts when there is consumer learning than when there is no consumer learning. This is because the firms' marketing effort can not only improve the market demand in the current period but the consumers' belief of the product value in the future periods. The firms' marketing efforts is decreasing over periods. The firms exert more effort in the early periods to boost the brand image and increase the future revenue. Over time, the true value of the product is gradually revealed and the equilibrium marketing effort levels drop.

We also find that information asymmetry is beneficial in the supply chain with valuation uncertainty and consumer learning. The supply chain makes a higher total profit when there is information asymmetry between the supplier and retailer. This result complements to the literature on strategic consumers. For example, Su and Zhang find that a decentralized supply chain yields a higher profit than a centralized supply chain when the consumers decide on the purchase timing [22]. In our paper, consumer learning induces both the supplier and the retailer to exert higher marketing efforts, which mitigates the adverse consequences of double moral hazard.

This research can be extended in several directions. First, we considered only a single retailer (or retail market), whereas in practice, a new product may be carried by multiple retailers. For example, fashion apparel comes into the consumer's eyeshot in several market areas. A consumer's belief and behavior are often influenced by the activities in other markets. The impact of consumer learning on the dynamics between multiple retail markets in the supply chain should be investigated. Second, this paper assumes the market demand can always be fulfilled. In supply chains, supply and demand often mismatch because of long production and shipping lead time. It would be interesting to examine the impact of product availability on the firm's marketing and other operational strategies in a supply chain with consumer learning. Third, firms often face the challenges of properly pricing a new product in presence of valuation uncertainty. Future research can examine the firms' pricing decisions in the product life cycle when there is consumer learning.

\section{Acknowledgments}

This research was supported in part by the Humanities and Social Sciences Foundation of Ministry of Education of China (12YJC630320), National Nature Science Foundation of China (71202066, 71172174, 70772073), Ph.D. Programs Foundation of Ministry of Education of China (20110075110003), Innovation Foundation of Educational Commission of Shanghai of China (12ZS58).

\section{Appendix A. Proof}

\section{A.1. Proof of Lemma 1}




$$
\begin{aligned}
& \text { Since } \tau_{t}=\frac{\sigma_{\theta_{t-1}}^{2}}{\sigma_{\theta_{t-1}}^{2}+\sigma_{\varepsilon}^{2}} \text { and } \frac{1}{\sigma_{\theta_{t}}^{2}}=\frac{1}{\sigma_{\theta}^{2}}+(t-1) \frac{1}{\sigma_{\varepsilon}^{2}} \text {, we have } \\
& \begin{aligned}
\pi t & =\frac{\sigma_{\theta_{t-1}}^{2}}{\sigma_{\theta_{t-1}}^{2}+\sigma_{\varepsilon}^{2}} \\
= & \frac{1+\sigma_{\varepsilon}^{2}\left(\frac{1}{\sigma_{\theta}^{2}}+(t-2) \frac{1}{\sigma_{\varepsilon}^{2}}\right)}{1} \\
= & \frac{1}{\frac{\sigma_{\varepsilon}^{2}}{\sigma_{\theta}^{2}}+t-1}
\end{aligned}
\end{aligned}
$$

$\tau_{t}$ is decreasing in $\sigma_{\varepsilon}^{2}$ and $t$, and increasing in $\sigma_{\theta}^{2}$.

\section{A.2. Proof of Lemma 2}

According to normal learning theory, the sequence variances are given by

$$
\tau_{t}=\frac{\sigma_{\theta_{t-1}}^{2}}{\sigma_{\theta_{t-1}}^{2}+\sigma_{\varepsilon}^{2}} \text { where } \frac{1}{\sigma_{\theta_{t-1}}^{2}}=\frac{1}{\sigma_{\theta_{t-1}}^{2}}+\frac{1}{\sigma_{\varepsilon}^{2}}=\frac{1}{\sigma_{\theta}^{2}}+(t-2) \frac{1}{\sigma_{\varepsilon}^{2}}
$$

With Eq. (A.1) above, we have

$$
\begin{aligned}
\tau_{t}=\frac{\sigma_{\theta}^{2}}{\sigma_{\varepsilon}^{2}+(t-1) \sigma_{\theta}^{2}} . & \\
\tau_{t}\left(1-\tau_{t+1}\right) & =\frac{\sigma_{\theta}^{2}}{\sigma_{\varepsilon}^{2}+(t-1) \sigma_{\theta}^{2}}\left(1-\frac{\sigma_{\theta}^{2}}{\sigma_{\varepsilon}^{2}+t \sigma_{\theta}^{2}}\right) \\
& =\frac{\sigma_{\theta}^{2}}{\sigma_{\varepsilon}^{2}+(t-1) \sigma_{\theta}^{2}}\left(\frac{\sigma_{\varepsilon}^{2}+(t-1) \sigma_{\theta}^{2}}{\sigma_{\varepsilon}^{2}+t \sigma_{\theta}^{2}}\right) \\
& =\frac{\sigma_{\theta}^{2}}{\sigma_{\varepsilon}^{2}+t \sigma_{\theta}^{2}} \\
& =\tau_{t+1} .
\end{aligned}
$$

Rewrite the above equation, we have 


$$
\tau_{t+1}=\frac{\tau_{t}}{1+\tau_{t}}
$$

When $\mathrm{t}=2$..N, we have $\tau \mathrm{t}+1<\tau \mathrm{t}$.

\section{A.3. Proof of Lemma 3}

The expected market demand for period $t, d_{t}$, can be represented by

$$
\begin{aligned}
& E\left[d_{t} \mid D_{t-1}\right]=E\left[\theta \mid D_{t-1}\right]+y_{t}+x_{t}, \\
& E\left[d_{t+1} \mid D_{t}\right]=E\left[\theta \mid D_{t}\right]+y_{t+1}+x_{t+1}, \\
& E\left[d_{t+2} \mid D_{t+1}\right]=E\left[\theta \mid D_{t+1}\right]+y_{t+2}+x_{t+2}
\end{aligned}
$$

We have

$$
\begin{aligned}
& E\left[\theta \mid D_{t}\right]=\left(1-\tau_{t+1}\right) E\left[\theta \mid D_{t-1}\right]+\tau_{t+1}\left(d_{t}-\bar{y}_{t}-\bar{x}_{t}\right) \\
& E\left[\theta \mid D_{t+1}\right]=\left(1-\tau_{t+2}\right) E\left[\theta \mid D_{t}\right]+\tau_{t+2}\left(d_{t+1}-\bar{y}_{t+1}-\bar{x}_{t}\right)
\end{aligned}
$$

Therefore

$$
\begin{aligned}
E\left[d_{t} \mid D_{t-1}\right]= & E\left[\theta \mid D_{t-1}\right]+y_{t}+x_{t}, \\
E\left[d_{t+1} \mid D_{t}\right]= & \left(\left(1-\tau_{t+1}\right) E\left[\theta \mid D_{t-1}\right]+\tau_{t+1}\left(d_{t}-\bar{y}_{t}-\bar{x}_{t}\right)\right)+y_{t+1}+x_{t+1}, \\
E\left[d_{t+2} \mid D_{t+1}\right]= & \left(\left(1-\tau_{t+2}\right) E\left[\theta \mid D_{t}\right]+\tau_{t+2}\left(d_{t+1}-\bar{y}_{t+1}-\bar{x}_{t+1}\right)\right)+y_{t+2}+x_{t+2} \\
= & \left(\left(1-\tau_{t+2}\right)\left(\left(1-\tau_{t+1}\right) E\left[\theta \mid D_{t-1}\right]+\tau_{t+1}\left(d_{t}-\bar{y}_{t}-\bar{x}_{t}\right)\right)\right. \\
& \left.+\tau_{t+2}\left(d_{t+1}-\bar{y}_{t+1}-\bar{x}_{t+1}\right)\right)+y_{t+2}+x_{t+2} .
\end{aligned}
$$

The first-order derivatives of $d_{t}, d_{t}+1$ and $d_{t}+3$ with respect to $x_{t}$ are

$$
\frac{\partial E\left[d_{t} \mid D_{t-1}\right]}{\partial x_{t}}=1, \frac{\partial E\left[d_{t+1} \mid D_{t}\right]}{\partial x_{t}}=\tau_{t+1}, \frac{\partial E\left[d_{t+2} \mid D_{t+1}\right]}{\partial x_{t}}=\tau_{t+1}\left(1-\tau_{t+2}\right) .
$$

Similarly, we can derive $\frac{\partial E\left[d_{t i \mid} \mid D_{t+i-1}\right]}{\partial x_{t}}$ as $\frac{\partial E\left[d_{t+i} \mid D_{t+i-1}\right]}{\partial x_{t}}=\tau_{t+1} \prod_{k=2}^{i}\left(1-\tau_{t+k}\right), i=1 \ldots N-t$.

Based on Lemma $2, \tau_{t}\left(1-\tau_{t+1}\right)=\tau_{t+1}$, we have 


$$
\frac{\partial E\left[d_{t+2} \mid D_{t+1}\right]}{\partial x_{t}}=\tau_{t+2}
$$

and

$$
\frac{\partial E\left[d_{t+i} \mid D_{t+i-1}\right]}{\partial x_{t}}=\tau_{t+i}, i=1 . . N-t .
$$

Since $0<\tau_{t}<1, t=2 . . N-1, \tau_{t}>\tau_{t+1}$, we have

$$
\frac{\partial E\left[d_{t} \mid D_{t-1}\right]}{\partial x_{t}}>\frac{\partial E\left[d_{t+1} \mid D_{t}\right]}{\partial x_{t}}>\frac{\partial E\left[d_{t+2} \mid D_{t+1}\right]}{\partial x_{t}}>\ldots>\frac{\partial E\left[d_{N} \mid D_{N-1}\right]}{\partial x_{t}}
$$

That is

$$
\frac{\partial E\left[d_{t} \mid D_{t-1}\right]}{\partial x_{t}}>\frac{\partial E\left[d_{t+i} \mid D_{t+i-1}\right]}{\partial x_{t}}, i=1 \ldots N-t, t=2 . . N-1 .
$$

With the same logic, we derive the relationships of the market demand $d_{t}$ and $y_{t}$ accordingly.

\section{A.4. Proof of Proposition 1}

1. In the period $t(1<t<\mathrm{N})$, The supplier's optimization problem in period $t$ is represented by

$$
\prod_{t}^{m l}=\max _{\phi, x_{t} y_{t}} \sum_{t=1}^{N} E\left[p d_{t}-C_{s}\left(x_{t}\right)-C_{r}\left(y_{t}\right) \mid D_{t-1}\right] .
$$

Differentiate $\prod_{t}^{m l}$ with respect to $x_{t}$, we have

$$
\begin{aligned}
& \frac{\partial \prod_{t}^{m l}}{\partial x_{t}}=\sum_{i=0}^{N-t} E\left[p\left[\frac{\partial d_{t+i}}{\partial x_{t}} \mid D_{t+i-1}\right]-C_{s}^{\prime}\left(x_{t}\right)\right], \\
& p \sum_{i=0}^{N-t}\left[\frac{\partial E\left[d_{t+i} \mid D_{t+i-1}\right]}{\partial y_{t}}\right]-C_{s}^{\prime}\left(x_{t}^{m l}\right)=0 .
\end{aligned}
$$

Based on Lemma 3, we have 


$$
\begin{gathered}
\frac{\partial E\left[d_{t} \mid D_{t-1}\right]}{\partial x_{t}}=1, \frac{\partial E\left[d_{t+1} \mid D_{t+i-1}\right]}{\partial x_{t}}=\tau_{t+i}, i=1 . . N-t . \\
p\left[1+\sum_{i=1}^{N-t} \tau_{t+i}\right]-C_{s}^{\prime}\left(x_{t}^{m l}\right)=0 .
\end{gathered}
$$

We therefore have

$$
\begin{aligned}
& C_{s}^{\prime}\left(x_{t}^{m l}\right)=p\left[1+\sum_{i=1}^{N-t} \tau_{t+i}\right], t=2 \ldots N-1 \\
& C_{s}^{\prime}\left(x_{N}^{m l}\right)=p .
\end{aligned}
$$

Similarly, base on the first order condition of $\prod_{t}^{m l}$ respect to $y_{t}$, we have

$$
p\left[1+\sum_{i=1}^{N-t} \tau_{t+i}\right]-C_{r}^{\prime}\left(y_{t}^{m l}\right)=0 .
$$

The retailer's effort is given by

$$
\begin{aligned}
C_{r}^{\prime}\left(y_{t}^{m l}\right)= & p\left[1+\sum_{i=1}^{N-t} \tau_{t+i}\right], t=2 \ldots N-1 \\
& C_{r}\left(y_{N}^{m l}\right)=p .
\end{aligned}
$$

2. From Eq. (A.2), the supplier's effort is decided by $\mathrm{p}$ and $\tau t$. Since $\mathrm{p}>0, \tau t>0, t=2 \ldots N-1$, and as $t$ increase, the expression

$$
\begin{aligned}
& {\left[1+\sum_{i=1}^{N-t} \tau_{t+i}\right], t=2 \ldots N-1 \text { has less terms, we have } C_{s}^{\prime}\left(x_{t}^{m l}\right)>C^{\prime} s} \\
& \left(x_{t-1}^{m l}\right), t=2 \ldots N .
\end{aligned}
$$

Similarly, we have $C_{r}^{\prime}\left(y_{t}^{m l}\right)>C^{\prime}{ }_{r}\left(y_{t-1}^{m l}\right)$.

3. Compare Eq. (3) with Eq. (A.2), we have $x^{m n}<x_{t}^{m l}$ and $v y^{m n}<y_{t}^{m l}$, when $t<N$.

\section{A.5. Proof of Proposition 2}

We first consider the retailer's problem in period $N$ 


$$
\pi_{N}^{a l}=\max _{y N}\left(E\left[\phi p d_{N}-C_{r}(y N)\right] D_{N-1}\right)
$$

Based on the first order condition of $\pi_{N}^{a l}$ with respect to $y_{N}$ and Lemma 3, we have

$$
C_{r}^{\prime}\left(y_{N}^{a l}\right)=\phi p
$$

The supplier's optimization problem in period $N$ can be rewritten as

$$
\prod_{N}^{a l}=\max _{x_{N}}(1-\phi) p\left(E\left[d_{N-1}\right]\right)-C_{s}\left(x_{N}\right)
$$

Based on the first order condition of $\prod_{N}^{a l}$ with respect to $x_{N}$ and Lemma 3, we have

$$
C_{s}^{\prime}\left(x_{N}^{a l}\right)=(1-\phi) p
$$

In the period $t(1<t<\mathrm{N})$, The retailer optimization problem in period $t$ is represented by

$$
\pi_{t}^{a l}=\max _{y_{t}} \sum_{i=0}^{N-t} E\left[\phi p d_{t+i}-C_{r}\left(y_{t+i}\right) \mid D_{t+i-1}\right] .
$$

The marginal impact of a retailer's effort is

$$
\frac{\partial \pi_{t}^{a l}}{\partial y_{t}}=\sum_{i=0}^{N-t} E\left[\phi p\left[\frac{\partial d_{t+i}}{\partial y_{t}} D_{t+i-1}\right]-C_{r}^{\prime}\left(y_{t}\right)\right] .
$$

Based on Lemma 3, we have

$$
\frac{\partial E\left[d_{t} \mid D_{t-1}\right]}{\partial y_{t}}=1, \frac{\partial E\left[d_{t+i} \mid D_{t+i-1}\right]}{\partial y_{t}}=\tau_{t+i}, i=1 . . N-t .
$$

Based on the first order condition of $\prod_{N}^{a l}$ with respect to $y_{t}$, we have

$$
\phi p \sum_{i=0}^{N-t}\left[\frac{\partial E\left[d_{t+i} \mid D_{t+i-1}\right]}{\partial y_{t}}\right]-C_{r}^{\prime}\left(y_{t}^{a l}\right)=0 .
$$

The retailer's effort is given by 
$C_{r}^{\prime}\left(y_{t}^{a l}\right)=\phi p\left[1+\sum_{i=1}^{N-t} \tau_{t+i}\right], t=2 \ldots N-1$

The supplier's expected profit is

$$
\Pi_{t}^{a l}=\max _{x_{t}} \sum_{i=0}^{N-t} E\left[(1-\phi) p d_{t+i}-C_{s}\left(x_{t+i}\right) \mid D_{t+i-1}\right] .
$$

The marginal impact of a supplier's effort on its profit is

$$
\frac{\partial \prod}{\partial x_{t}}=\sum_{i=0}^{N-t} E\left[(1-\phi) p\left[\frac{\partial d_{t+i}}{\partial x_{t}} D_{t+i-1}\right]-C_{s}^{\prime}\left(x_{t}\right)\right] .
$$

Based on the first order condition of $\prod_{N}^{a l}$ with respect to $x_{t}$, we have

$$
(1-\phi) p \sum_{i=0}^{N-t}\left[\frac{\partial E\left[d_{t+i} \mid D_{t+i-1}\right]}{\partial x_{t}}\right]-C_{s}^{\prime}\left(x_{t}^{a l}\right)=0 .
$$

The supplier's effort is given by

$$
C_{s}^{\prime}\left(x_{t}^{a l}\right)=(1-\phi) p\left[1+\sum_{i=1}^{N-t} \tau_{t+i}\right], t=2 \ldots N-1
$$

\section{A.6. Proof of Proposition 3}

Form Eq. (A.5), the supplier's effort is decided by $\phi, \mathrm{p}$ and $\tau t$. Since $1>\phi>0, p>0, \tau_{t}>0, t=2 . . N-1$, we have $C_{s}^{\prime}\left(x_{t}^{a l}\right)>C_{s}^{\prime}\left(x_{t-1}^{a l}\right), t=2 \ldots N$.

Similarly, we have $C_{r}^{\prime}\left(y_{t}^{a l}\right)>C_{r}^{\prime}\left(y_{t-1}^{a l}\right)$.

Given a fixed positive sharing ratio $\phi$, compare Eq. (4) with Eq. (A.5), we have $x^{a n}<x_{t}^{a l}$. Similarly, we get $y^{a n}<y_{t}^{a l},(t<N)$.

Compare Eq. (8) with Eq. (A.5), we have $x_{t}^{a l}<x^{m l}$ and $y_{t}^{a l}<y^{m l}, t<N$.

\section{A.7. Proof of Proposition 4}

At the beginning of the horizon, the supplier determines the revenue sharing factor $\phi$. 


$$
\prod_{t}^{a l}=\max _{\phi} \sum_{i=0}^{N-t} E\left[(1-\phi) p d_{t+i}-C_{s}\left(x_{t}\right) \mid D_{t+i-1}\right] .
$$

Using the first order condition with respect to $\phi$, we get

$$
\begin{aligned}
0= & -\left(\theta_{0}+y_{1}+x_{1}\right)+(1-\phi)\left(\frac{\partial y_{1}}{\partial \phi}\right) \\
& -\left(\left(\left(1-\tau_{2}\right) \theta_{0}+\tau_{2}\left(\theta_{0}+y_{1}+x_{1}-\bar{y}_{1}-\bar{x}_{1}\right)\right)+y_{2}+x_{2}\right) \\
& +(1-\phi)\left(\tau_{2}\left(\frac{\partial y_{1}}{\partial \phi}-\partial \frac{\bar{y}_{1}}{\partial \phi}-\partial \frac{\bar{x}_{1}}{\partial \phi}\right)+\frac{\partial y_{2}}{\partial \phi}\right) \\
& -\left(\begin{array}{c}
\left(1-\tau_{3}\right)\left(\left(1-\tau_{2}\right) \theta_{0}+\tau_{2}\left(\theta_{0}+y_{1}+x_{1}-\bar{y}_{1}-\bar{x}_{1}\right)\right) \\
+\tau_{3}\left(\theta_{0}+y_{2}+x_{2}-\bar{y}_{2}-\bar{x}_{2}\right)+y_{3}+x_{3}
\end{array}\right) \\
& +(1-\phi)\left(\left(1-\tau_{3}\right) \tau_{2}\left(\frac{\partial y_{1}}{\partial \phi}-\frac{\partial \bar{y}_{1}}{\partial \phi}-\frac{\partial \bar{x}_{1}}{\partial \phi}\right)+\tau_{3}\left(\frac{\partial y_{2}}{\partial \phi}-\frac{\partial \bar{y}_{2}}{\partial \phi}-\frac{\partial \bar{x}_{2}}{\partial \phi}\right)+\frac{\partial y_{3}}{\partial \phi}\right) \\
& \ldots
\end{aligned}
$$

That is

$$
\begin{aligned}
0= & -\left(\theta_{0}+y_{1}+x_{1}\right)+(1-\phi)\left(\frac{\partial y_{1}}{\partial \phi}\right) \\
& -\left(\theta_{0}+y_{2}+x_{2}\right)+(1-\phi)\left(-\tau_{2}\left(\frac{\partial \bar{x}_{1}}{\partial \phi}\right)+\frac{\partial y_{2}}{\partial \phi}\right) \\
& -\left(\theta_{0}+y_{3}+x_{3}\right)+(1-\phi)\left(-\left(1-\tau_{3}\right) \tau_{2} \frac{\partial \bar{x}_{1}}{\partial \phi}-\tau_{3} \frac{\partial \bar{x}_{2}}{\partial \phi}+\frac{\partial y_{3}}{\partial \phi}\right)
\end{aligned}
$$

From Lemma 2, we have ${ }^{\tau_{t+1}}=\tau_{t}\left(1-\tau_{t+1}\right)$

$$
\begin{aligned}
0= & -\left(\theta_{0}+y_{1}+x_{1}\right)+(1-\phi)\left(\frac{\partial y_{1}}{\partial \phi}\right) \\
& -\left(\theta_{0}+y_{2}+x_{2}\right)+(1-\phi)\left(-\tau_{2}\left(\frac{\partial \bar{x}_{1}}{\partial \phi}\right)+\frac{\partial y_{2}}{\partial \phi}\right) \\
& -\left(\theta_{0}+y_{3}+x_{3}\right)+(1-\phi)\left(-\tau_{3}\left(\frac{\partial \bar{x}_{1}}{\partial \phi}+\frac{\partial \bar{x}_{2}}{\partial \phi}\right)+\frac{\partial y_{3}}{\partial \phi}\right)
\end{aligned}
$$

We therefore have

$$
\phi=1-\frac{\sum_{t=1}^{N}\left(\theta_{0}+y_{t}+x_{t}\right)}{\sum_{t=1}^{N} \frac{\partial y_{t}}{\partial \phi}-\sum_{t-1}^{N-1}\left(\tau_{t+1}\left(\sum_{i=1}^{t} \frac{\partial \bar{x}_{i}}{\partial \phi}\right)\right)} .
$$




\section{References}

[1] Apple reports fourth quarter results. Apple's Earning Release available at, http://www. apple.com/pr/library/2011/10/18Apple-Reports-Fourth-Quarter-Results.html2011.

[2] S. Bhattacharyya, F. Lafontaine, Double-sided moral hazard and the nature of share contracts, Rand Journal of Economics 26 (4) (1995) 761-781.

[3] G.P. Cachon, Supply chain coordination with contracts, In: in: S. Graves, T. de Kok (Eds.), Handbooks in Operations Research and Management Science: Supply Chain Management, North Holland, 2003, pp. 227-339, Ch11.

[4] G.P. Cachon, M.A. Lariviere, Supply chain coordination with revenue-sharing contracts: strengths and limitations, Management Science 51 (1) (2005) 30-44.

[5] C.J. Corbett, G.A. DeCroix, Shared savings contracts for indirect materials in supply chains: channel profits and environmental impacts, Management Science 47 (7) (2001) 881-893.

[6] P.S. Desai, Advertising fee in business-format franchising, Management Science 43 (10) (1997) 1401-1419.

[7] P.S. Desai, K. Srinivasan, Demand signaling under unobservable effort in franchising: linear and nonlinear price contracts, Management Science 41 (10) (1995) 1608-1623.

[8] W. Duan, B. Gu, A.B. Whinston, Do online reviews matter? An empirical investigation of panel data, Decision Support Systems 45 (4) (2008) 1007-1016.

[9] M. Eswaran, A. Kotwal, Theory of contractual structure in agriculture, American Economic Review 75 (3) (1985) 352-367.

[10] G. Gallego, R. Phillips, O. Sahin, Strategic management of distressed inventory, Production and Operation Management 17 (4) (2008) 402-415.

[11] V. Gaur, Y.H. Park, Asymmetric consumer learning and inventory competition, Management Science 53 (2) (2007) 227-240.

[12] Z.L. Guo, Optimal decision making for online referral marketing, Decision Support Systems 52 (2) (2012) 373-383.

[13] B. Holmstrom, Managerial incentive problems: a dynamic perspective, Review of Economic Studies 66 (1) (1999) 169-182.

[14] Z. Huang, S.X. Li, Co-op advertising models in manufacturer-retailer supply chains: a game theory approach, European Journal of Operational Research 135 (2001) 527-544. 
[15] S.K. Kim, S. Wang, Linear contracts and the double moral-hazard, Journal of Economic Theory 82 (2) (1998) 342-378.

[16] R. Lal, Improving channel coordination through franchising, Marketing Science 9 (4) (1990) 299-318.

[17] H.L. Lee, K.C. So, C.S. Tang, The value of information sharing in a two-level supply chain, Management Science 46 (5) (2000) 626-643.

[18] Q. Liu, G. van Ryzin, Strategic capacity rationing when customers learn, Manufacturing \& Service Operations Management 13 (1) (2011) 89-107.

[19] R.J. Meyer, S.H. Zhao, J.K. Han, Biases in valuation vs. usage of innovative product features, Management Science 27 (6) (2008) 1083-1096.

[20] J.F. Muth, Rational expectations and the theory of price movements, Econometrics 29 (1961) 315-335.

[21] A. Ovchinnikov, J.M. Milner, Revenue management with end-of-period discounts in the presence of customer learning, Production and Operations Management 20

(6) (2011) 1937-5956.

[22] X. Su, F. Zhang, Strategic customer behavior, commitment, and supply chain performance, Management Science 54 (10) (2008) 1759-1773.

[23] R. Swinney, Selling to strategic consumers when product value is uncertain: the value of matching supply and demand, Management Science 57 (10) (2011) 1737-1751.

Dr. Jianheng Zhou is an associate professor at the Glorious Sun School of Business and Economics, Donghua University, China. She received her Ph.D. degree from Donghua University. Her research interests include supply chain management, logistics management and supply chain optimization. She has published papers in Journal of Systems \& Management, Industrial Engineering and many conference proceedings.

Dr. Xia Zhao is an assistant professor of Information Systems at the Bryan School of Business and Economics, the University of North Carolina at Greensboro. She received her Ph.D. degree in Management Science and Information Systems from the McCombs School of Business at the University of Texas at Austin. Her research interests include online advertising, information security, electronic commerce and IT governance. She has published papers in Journal of Management Information Systems, Decision Support Systems, IEEE Computer, International Journal of Electronic Commerce, Information Systems Frontier and many conference proceedings.

Dr. Ling Xue is an assistant professor at the Department of Management Information Systems, Fogelman College of Business and Economics, the University of Memphis. He received his 
Ph.D. degree in Management Science and Information Systems from the McCombs School of Business at the University of Texas at Austin. His research interests are in the areas of IT governance, the business value of IT, electronic commerce and information security. His papers have been published in Information Systems Research, MIS Quarterly, Journal of Management Information Systems, International Journal of Electronic Commerce, Journal of Global Information Management and the proceedings of International Conference on Information Systems.

Dr. Vidyaranya Gargeya is a professor of OperationsManagement at the Bryan School of Business and Economics, the University of North Carolina at Greensboro. He received his Ph.D. degree in Business Administration from Georgia State University. His research interests include supply chain management, global operations strategy, performance measurement, customer relationship management, quality, and continuous improvement. Vidyaranya has published papers in Journal of Operations Management, Technovation, Transportation Research (Part E), The Journal of the Textile Institute, Business Process Management Journal, International Journal of Production Research, Omega, International Journal of Quality and Reliability Management, Case Research Journal, Clothing and Textiles Research Journal, etc. He co-authored a book titled "Customer Relationship Management: A Global Perspective". Dr. Gargeya served on the Board of Examiners of Malcolm Baldrige National Quality Award and the North Carolina Awards for Excellence and has also consulted with Fortune 500 companies. 